ISSN: 0514-7336

DOI: https://doi.org/10.14201/zephyrus201779103125

\title{
LA IDENTIFICACIÓN DEL CATASTRO RURAL ROMANO A TRAVÉS DE LOS FUNDI. UNA METODOLOGÍA APLICADA EN EL AGER ILIBERRITANVS
}

\section{Detection of Roman rural cadasters through fundi. A methodology applied in ager Iliberritanus}

\author{
Mario Gutiérrez-Rodríguez, Margarita Orfila Pons y Elena H. SÁnchez-López \\ Dpto. de Prehistoria y Arqueología. Facultad de Filosofia y Letras-UGR. Campus Universitario de Cartuja, s/n. 18071 \\ Granada. Grupo HUм 296, Arqueología de época clásica y Antigüedad Tardía en Andalucía Oriental. Correo-e: \\ mgrodriguez@ugr.es; orfila@ugr.es; elenasanchez@ugr.es
}

Recepción: 12/02/2016; Revisión: 7/07/2017; Aceptación: 2/03/2017

\begin{abstract}
Resumen: El estudio de los paisajes rurales antiguos se ha visto enriquecido por una mayor comprensión de las villae y otras formas de asentamiento rural. Estas instalaciones agrícolas son, en muchos casos, el único registro arqueológico visible de una realidad normalmente perdida del paisaje agrario romano: los fundi. En este trabajo proponemos una metodología para identificar catastros romanos, usando las variables cuantitativas y cualitativas que las villae ofrecen: visibilidad, prominencia topográfica, cronología, orientación, distancia entre asentamientos, cercanía a ejes teóricos, etc. Para ello, se examina el caso de estudio del territorio asignado a Florentia Iliberritana, la ciudad de Granada en época romana. Como resultado de la investigación llevada a cabo en las últimas décadas, se ha identificado una alta densidad de instalaciones agropecuarias en el área periurbana, cuyo momento fundacional coincide con la adquisición de estatuto municipal por parte de la urbs. La aplicación de las variables anteriormente citadas, junto con las metodologías consolidadas en la historiografía, como el análisis regresivo del paisaje y el estudio de documentación cartográfica y archivística, ha permitido identificar una centuriatio de módulo de $20 \times 20$ actus con divisiones internas de $10 \times 10$ actus.

Palabras clave: Florentia Iliberritana; paisaje agrario; Sistemas de Información Geográfica; catastro; villae.

АвSтRACT: A better understanding of villae and other forms of rural settlement has enriched the study of ancient rural landscapes. These agricultural installations are, in many cases, the only visible archaeological records of a lost reality of the Roman agrarian landscape: the fundi. In this paper, we propose a methodology to identify Roman cadasters, using the qualitative and quantitative variables that villae offer: viewshed, topographic prominence, chronology, orientation, distance between villae, closeness to the theoretical axes etc. To do this, we examine the case-study of the territory assigned to Florentia Iliberritana, the city of Granada in Roman times. As a result of the research carried out in the last decades, it has been identified a high density of agricultural settlements in the peri-urban area, whose construction coincides with the acquisition of municipal status by the urbs. The application of the aforementioned variables, along with established methodologies in historiography as the regressive analysis of the landscape and the study of cartographic and archival documentation as well, has allowed to identified a $20 \times 20$ actus centuriation with internal divisions of $10 \times 20$ actus.
\end{abstract}

Key words: Florentia Iliberritana; agrarian landscape; Geographical Information Systems; cadastre; villae. 


\section{Introducción ${ }^{1}$}

Como cualquier acción antrópica, las parcelaciones rurales romanas modificaron de un modo u otro el paisaje que las enmarcaba, dejando en él su impronta con viales y solares que quedaron plasmados sobre el terreno. Nos referimos a los agri limita$t i$, esas parcelas cultivables del ager publicus medidas con exactitud por los agrimensores para ser asignadas a colonos adscritos a una ciuitas. Si su categoría estatutaria fuese de colonia, esa acción se llevaría a cabo una vez dictaminada la lex agraria correspondiente -en la que se definía el tipo de tierras a dividir; la calidad de las mismas; el tipo de beneficiarios, que en la mayoría de los casos eran veteranos; la modalidad de distribución o, lo que es lo mismo, los lotes creados- (Moatti, 1993: 7-30; Chouquer y Favory, 2001: 111-136). Sin embargo, estas divisiones también se realizaron en territorios de $m u$ nicipia, sin necesidad de deductio. Las parcelaciones son reflejo del tipo de ocupación del territorio por parte del Estado romano, y de su administración (Chic, 2000: 101). Con este modelo se establecía la naturaleza jurídica de las tierras y de su puesta en valor, convirtiéndose éstas en un espacio tributario. Estos parcelarios reflejan hoy el efecto tangible de una acción intangible, como lo fue la implantación de ese sistema de control fiscal, es decir, de un catastro (Chevallier, 1974; Chouquer et al., 1983: 39). Ello, al mismo tiempo, permitía al Estado tener a sus habitantes localizados (Prieto, 2002: 161). Por otra parte, los paisajes centuriados tienen una inherente lectura ideológica. Además de un sistema de división y asignación de la tierra, el ager divisus et adsignatus supone una verdadera apropiación conceptual del paisaje fundamentada en un sistema mítico y religioso, simbolizando una 'idea' y un modelo de cómo concebir y organizar el territorio

1 El presente trabajo se ha realizado en el marco de los Proyectos de Investigación I + D + i HAR2009-11824 y HAR2013-41635-P y del contrato FPu13/02363 del Ministerio de Educación, Cultura y Deporte. Los autores agradecen los comentarios del Consejo Editorial de la revista, así como de los revisores anónimos que han contribuido a enriquecer el manuscrito original. ideal de una ciudad romana (Palet et al., 2010: 127; López Paz, 1994).

El establecimiento de este tipo de estructuras estaba ligado a los recursos que ofrecía el propio territorio y sus posibilidades de explotación, en donde el fundus era uno de los elementos esenciales de la vertebración del paisaje rural, reflejo de todo un sistema económico y cultural, además de ser un medio de explotación agropecuario.

No siempre es fácil reconocer sobre el terreno trazas fosilizadas de esa acción de parcelar. De hecho, han sido muchas las propuestas referidas al procedimiento de su identificación en la actualidad. No se va a realizar aquí un repaso a las obras que se han escrito sobre este tema. Sin embargo, no se puede dejar de mencionar el importante bagaje adquirido del estudio de las diferentes fuentes que conforman el Corpus Agrimensorum Romanorum (Blume et al., 1848-1852; Thullin, 1913; Carder, 1978; Campbell, 2000; Guillaumin, 2005), así como la gran labor desarrollada en las últimas décadas del s. Xx por el equipo perteneciente a la Univ. de Besançon, liderado por M. Clavel-Levêquê, y sus múltiples publicaciones.

Lo que aquí planteamos es una opción de reconocimiento del parcelario, aun teniendo pocas trazas fosilizadas de esas divisiones. En este sentido, es importante valorar, en primer lugar, la naturaleza del territorio y sus posibilidades productivas. Hay que tener presente la orografía originaria, así como poder reconocer, a través de documentación arqueológica, la cronología de funcionamiento de las dependencias relacionadas con el funcionamiento de los fundi localizados en la zona. Hay que valorar el posicionamiento de cada una de esas construcciones, tanto entre ellas, como en relación a la distancia a la que se encuentran de la urbs a la que pertenecieron. Como es lógico, se debe contar con un número significativo de inmuebles identificados, susceptibles de ser posicionados sobre una planimetría. Las distancias plasmadas deben ser valoradas en medidas de superficie de época romana, en donde el valor del actus y sus posibles múltiplos, como el iuguerum o el heredium, deben estar siempre presentes. No en vano es habitual que en las fuentes literarias, cuando se contabilizan 
las tierras de una finca, su superficie se cuente en múltiplos de algunos de estos valores, como es el caso de Ausonio, que mide sus dominios en iugera (Escritos personales, XII, 2). Otro ejemplo significativo es la sortitio de Ilici, en donde el reparto de tierras se hace en lotes de trece iugera por cada veterano (Mayer y Olesti, 2001; Guillaumin, 2002). Estos últimos datos permitirán llevar a cabo una jerarquización de estos elementos en el territorio. Si la coincidencia entre distancias, y, por tanto, entre superficies que se asignan a cada una de las fincas de los establecimientos identificados arqueológicamente, es próxima a una de las medidas de superficie romanas, el siguiente paso a dar será analizar la orientación que tienen esas estructuras (Fig. 1) (Orfila, 2011-12; Orfila et al., 2014). Se deben tener presentes además todas las pautas ofrecidas por los agrónomos romanos en relación a las características constructivas y orientación (Guy, 1993; Roth-Congès, 1996). Tanto Varrón (I, 12, 3) como Columela (I, 4, 10), por ejemplo, dan indicaciones referentes al lugar en donde deben instalarse esas construcciones dentro de la finca, la necesidad de tener garantizada el agua potable, el poder poner en su alrededor un huerto, etc., así como la preocupación por la orientación a conferir a algunas de sus estancias para un mayor beneficio de la conservación de los productos: la cella uinaria al norte, la ollearia al sur, etc.

Aunque no quede claro si hubo una normativa que regulaba de manera más taxativa la ubicación de esas edificaciones dentro del fundus, en la que una de las causas fuera la cercanía a las redes de comunicación creadas en el momento de la implantación de ese parcelario ortogonal, la realidad es que sí pueden apreciarse, arqueológicamente, ciertas pautas. Tal como han comentado otros investigadores “... allí donde la retícula del catastro existe, la distribución de los hábitats obedece especialmente a un criterio de viabilidad. El rigor de las matrices ortogonales impone una uniformidad característica de las normas locales de situación, acceso y distribución de los habitantes"... (Chouquer et al., 1987: 285). Esta relación fundus-parcelación va más allá de la mera ubicación del poblamiento rural con respecto a los ejes viarios del parcelario, y llega a incidir en
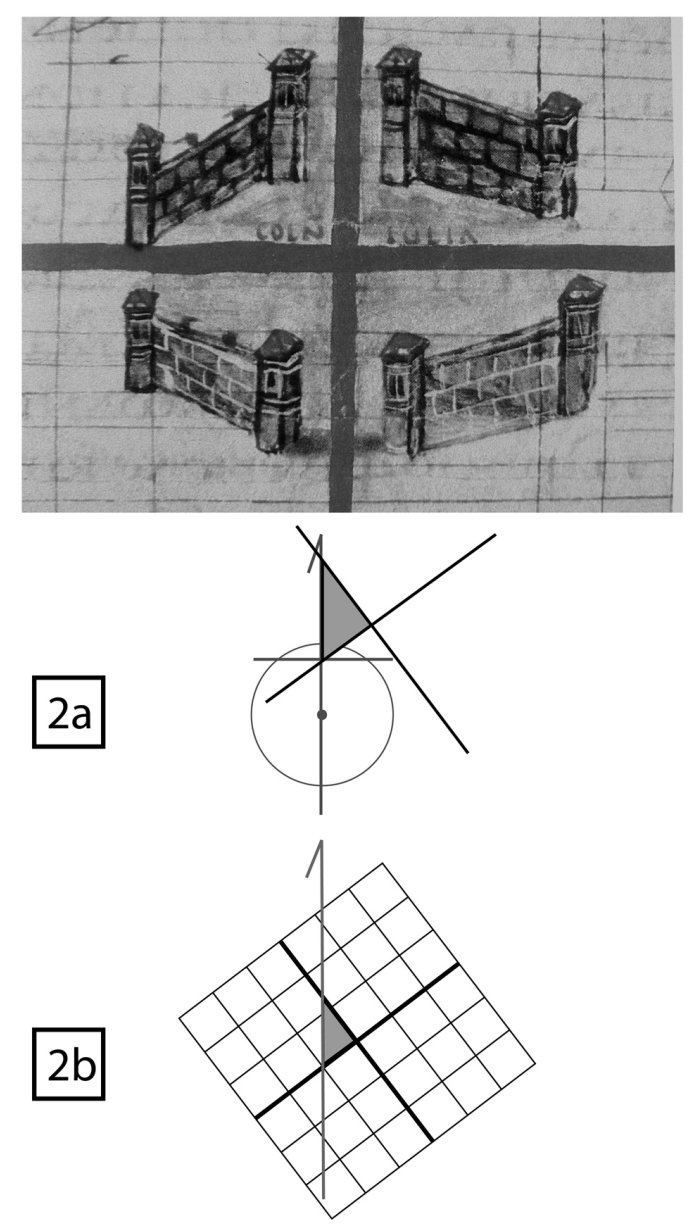
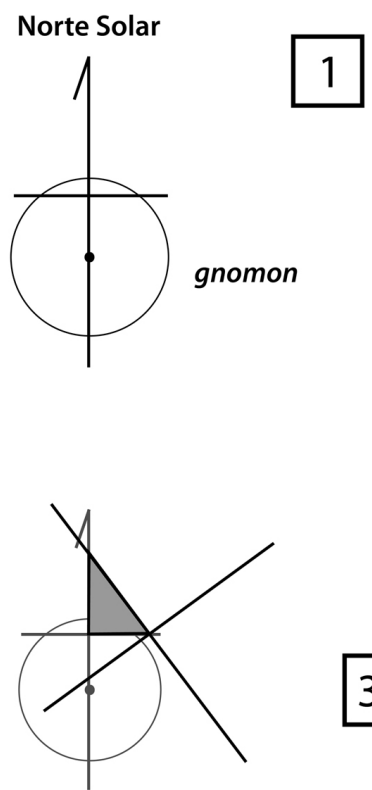

FIG. 1. Representación de una Colonia Iulia como modelo de ratio pulcherrima (miniatura del manuscrito Arcerianus A, Wolfenbüttel, Herzog August Bibliothek), y procedimiento de varatio (3a y 3b), con su variante utilizando ternas pitagóricas $(2 a, 2 b)$. 
otros aspectos como su orientación o las áreas de expansión progresiva de las instalaciones agropecuarias (Chouquer et al., 1987: 286). La uilla o explotación agropecuaria se convierte en la manifestación de una realidad normalmente inaprensible desde el punto de vista arqueológico, el fundus (Ariño et al., 2004: 156), base de la organización catastral. Cabe recordar casos como el del ager Collatinus (Quilici, 1974), donde las villae se adaptan muy bien a la trama teórica de 15 x 15 actus, manteniendo la misma orientación que el parcelario y la uia Latina. Esto sirvió a Chouquer y otros investigadores para apreciar la eficacia de la limitatio, y como criterio que justifica la identificación de la regularidad del parcelario (Chouquer et al., 1987: 287-288). A pesar de que el ager Collatinus es excepcional, tanto por la cantidad de documentación disponible como por su regularidad, esta situación se repite, aun con matices, en otros lugares. En el territorio adscrito a Bovillae las instalaciones rurales se ubican en los ejes de la pertica, aunque difieren en orientación con respecto a la trama (De Rossi, 1979), y en el ager Venafranus, recintos funerarios, mausoleos y villae tienen una relación clara con el catastro y las tramas identificadas (Chouquer y Favory, 1991). En otros casos esta situación fue intencionada, como en Forum Popilii, donde la red catastral integra lugares de época republicana que tenían una importante dimensión socioeconómica (Chouquer y Favory, 1991). Fuera de la Península Itálica también se aprecia este patrón en la distribución del poblamiento rural. En Béziers es habitual la presencia de instalaciones rurales a lo largo de los ejes de las centurias, así como en las subdivisiones internas. Lo mismo sucede en las centuriaciones Nîmes 'A' y 'B', Montpelliérais 'A' y 'B'y en la denominada centuriación Sextantio-Ambrussum, donde “... la relación privilegiada y significativa que la red mantiene con los sitios galorromanos identificados en la llanura, demuestra su función organizadora en la distribución de residencias y granjas, así como de necrópolis, aparentemente desde la época augústea”... (Chouquer y Favory, 1991: 197). La misma relación se encuentra en los territoria de Hispania. Algunos ejemplos destacados son las centuriaciones de Tarraco, Barcino e Ilici, donde instalaciones

(C) Universidad de Salamanca agropecuarias y necrópolis se ubican en cruces de caminos o a lo largo de kardines y decumani con cierta precisión estadística (Gurt et al., 1996; Palet et al., 2010; Palet y Orengo, 2010: 121-154). Uno de los casos mejor estudiados es el del ager tarraconensis, donde la distribución de asentamientos se relaciona con las vías y ejes de las tramas centuriadas. Es el caso de los asentamientos de la franja costera comprendida entre Salou y Cambrils que se relacionan con el trazado de la Via Augusta, o aquellos ubicados en el recorrido de la Via de Italia in Hispanias, como Centcelles, Mas Sardà, els Hospitals, etc. (Palet y Orengo, 2010: 142). Más allá de su ubicación, se han constatado casos donde estas arquitecturas mantienen la misma orientación que las tramas centuriadas, tanto en el caso de edificios públicos como aquellos de carácter privado. Entre los primeros cabe destacar los circos de Augusta Emerita y Calagurris, así como determinadas edificaciones públicas extramuros al s de Tarraco (Ariño et al., 2004: 165-173). De la arquitectura privada son ejemplos el sector so del suburbium de Tarraco (Adserias et al., 2000) o villae de su territorium. Es el caso de la relación que existe entre la orientación de la trama Tarraco III con las estructuras de Centcelles y el acueducto de Pont de les Caixes, o la trama Tarraco II con la villa de Mas d'en Gras (Palet y Orengo, 2010: 143-144). Además son ejemplo de esta situación las estructuras aparecidas en el Solar de la Clínica pertenecientes al ager de Calagurris (Andrés, 1998).

Aparte de los parámetros anteriormente referidos, es muy importante comprobar otras variables, como es la distancia de estas instalaciones respecto a la ciudad, si las construcciones de los fundi están en lugares prominentes o no, su dominio visual del paisaje, y tener presente toda la serie de accidentes geográficos de la zona que pudieron afectar a la hora de facilitar la división en parcelas de todo ese territorio. Es decir, implementar las posibilidades que ofrece el análisis espacial del territorio con tecnología SIG, con las propuestas que los autores clásicos dictan sobre las formas de organización del paisaje antiguo (Gutiérrez y Orfila, 2013-14: 450).

A partir de estos datos, debe crearse un módulo hipotético, identificado en relación a esas medidas 
de distancias y todos los parámetros citados. Entre los condicionantes que deben cumplirse se encuentra la repetición en las orientaciones de esos establecimientos rurales y que esta orientación encaje con los accidentes geográficos que caracterizan la zona objeto de estudio (véanse torrentes, ríos, fallas, montañas, línea de mar, etc.), de manera que se aprovechen al máximo las posibilidades de ese territorio. Surge así esa trama teórica, reflejo de un plausible parcelario. Si el resultado es positivo, siempre teniendo presente que se debe actuar con escalas adecuadas para la obtención de resultados óptimos, deben analizarse toda otra serie de documentos, en beneficio de una correcta interpretación: tanto a nivel archivístico como cartográfico o de fotografía aérea histórica, etc., para realizar un análisis arqueomorfológico del territorio. Así, el registro de vías, caminos secundarios, sistemas de regadío, límites agrarios, aglomeraciones rurales, etc., permite identificar fases cronológicas en base a la desaparición de los sistemas antiguos y su sustitución por otros posteriores, o bien por la pervivencia de las estructuras antiguas modificadas parcialmente para adaptarse al nuevo sistema. Unos planteamientos cercanos a nuestra propuesta metodológica podrían ser los de Barcino y Tarraco, pero desde una perspectiva

FIG. 2. Sitios arqueológicos del ager Iliberritanus citados en el texto:

1. Mondragones; 2. Armilla; 3. Laurel; 4. Gabia;

5. Primavera; 6. Ogijares; 7. Pago de Salazar;

8. Camino de Ronda, 97; 9. Hijar.

\section{年}

diferente, más centrada en cuestiones arqueomorfológicas (Palet y Orengo, 2010; Palet et al., 2010, entre otros). Con todo este bagaje, presentamos aquí los resultados obtenidos en los entornos de Granada, la antigua Florentia Iliberritana, que han sido positivos, tal como se apreciará en apartados siguientes.

\section{Ager Iliberritanus: percepción del poblamiento antiguo en un medio actualmente urbanizado}

Florentia Iliberritana, ubicada en lo que hoy día es el barrio del Albaicín granadino, fue en origen un asentamiento ibérico integrado en la órbita romana desde el s. II a. C. y que obtuvo su municipalización de manos de César o Augusto en el s. I a. C. Por

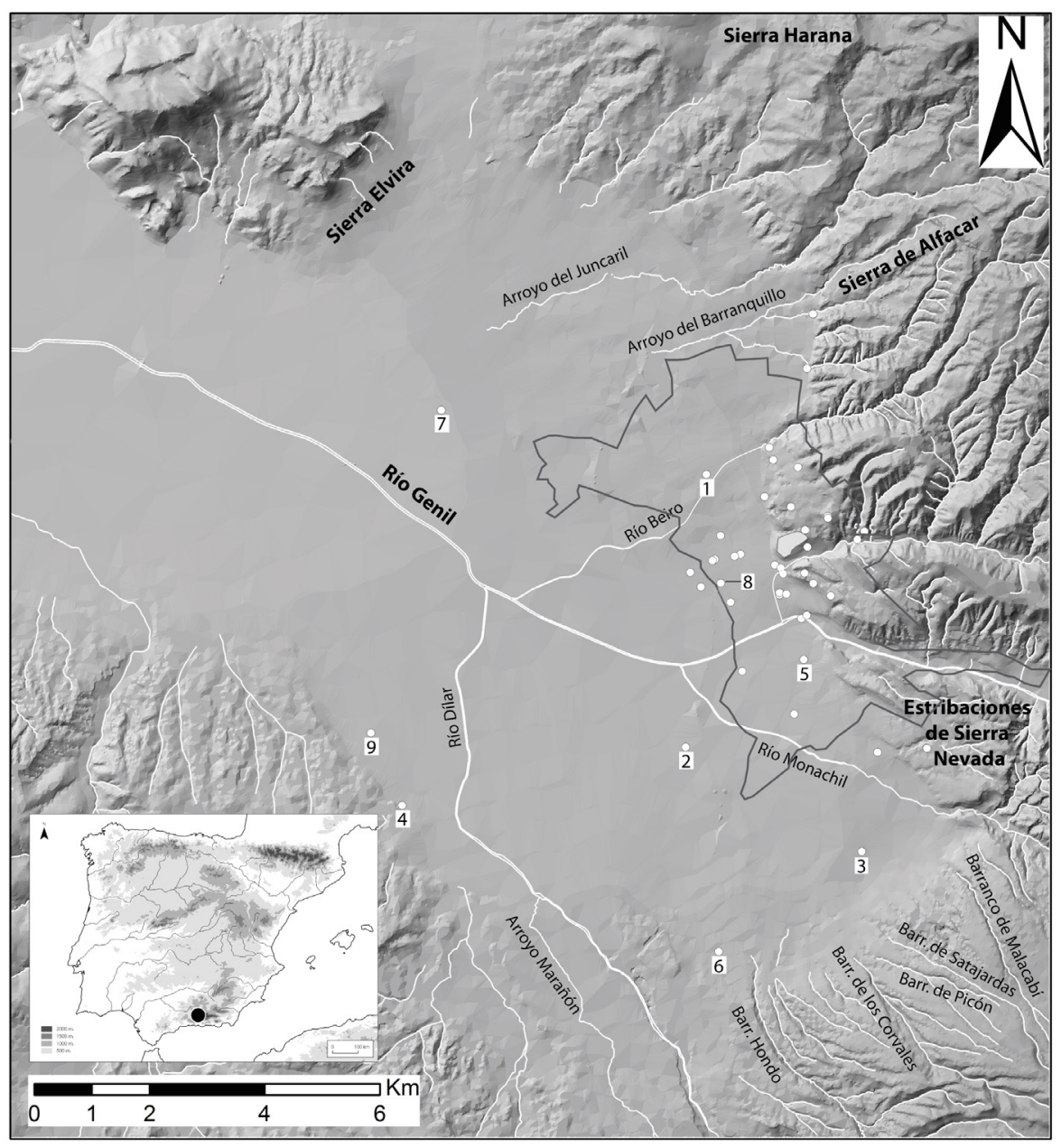

(C) Universidad de Salamanca 
su localización geográfica, la ciudad se encontró en la periferia de la prouincia Baetica (Orfila, 2011a), estando su territorio abocado a marcar el límite interprovincial con la vecina Tarraconensis.

Como ocurre en la mayoría de las ciudades romanas, el territorio dependiente de Florentia estuvo densamente poblado en la Antigüedad. Buena muestra de ello es el importante número de asentamientos rurales sacados a la luz por la intensa actividad arqueológica desarrollada en las dos últimas décadas en Granada y sus alrededores (Fig. 2). La finalidad de esta multitud de villae no fue otra que la explotación agropecuaria de la fértil Vega Granadina, surcada por el río Genil, el Singilis romano, y sus afluentes.

Resulta especialmente destacable la documentación, dentro de los límites de lo que hoy en día es el casco urbano de Granada, de numerosas villas que, por su proximidad a la ciudad antigua, podríamos definir como periurbanas. Entre ellas cabe mencionar la recientemente descubierta Villa de los Mondragones -excavada entre 2013 y 2014-, con una amplia variedad de elementos distribuidos en una superficie de $5000 \mathrm{~m}^{2}$, fechables entre los ss. I y viI d. C. Destacan la documentación de una necrópolis altoimperial; estructuras pertenecientes a la pars rustica y la pars urbana -incluida una amplia zona destinada al prensado de aceite y sus estructuras anexas-; una necrópolis tardoantigua -ss. IV-VII-; y un edificio tardío de posible funcionalidad religiosa -ss. VI-VII- (Rodríguez Aguilera et al., 2013-2014).

Paralelamente, la intensa actividad arqueológica derivada de la construcción del Metro Ligero de Granada ha supuesto la excavación, en el último lustro, de establecimientos rurales periurbanos en Camino de Ronda -a la altura del cruce con la c/ Recogidas y en su confluencia con la plaza Albert Einstein- y Campus Universitario de Fuentenueva (Rodríguez Aguilera et al., 2013-2014), que vienen a unirse al hallazgo de una uilla bajo la antigua estación de autobuses, también en Camino de Ronda, fechada entre la primera mitad del s. I y la primera mitad del s. III. Sus constructores trataron de resolver los problemas derivados de su ubicación en una zona inundable de la vega mediante grandes cimentaciones, que contribuían a aislar la obra de la humedad, así como una red de canales que drenarían las aguas superficiales (Navas et al., 2009). También es reciente la intervención, en el Pago de Salazar, ya en el término municipal de Maracena, donde se localizó un balneum adscrito a una villa con ocupación altoimperial.

A todos estos hallazgos recientes, deben añadirse aquellos realizados en décadas anteriores. Como la Villa de la c/ Primavera -o de Los Vergeles-, que experimenta su momento de mayor esplendor en los ss. IV-V, cuando es dotada de instalaciones termales y suntuosas estancias decoradas con mosaicos polícromos de temática esencialmente geométrica (Fresneda et al., 1993; Marín, 2011). O también los documentados desde el s. XIX más allá de este primer cinturón: Casería de Titos, Huétor Vega, Daragoleja, Gabia, Cortijo del Canal en Albolote, Híjar, Ogíjares, La Zubia, acceso a IEs Generalife, piscina Miami, etc. (Sánchez et al., 2008).

Muchos de estos establecimientos han mostrado fases de ocupación desde el s. I d. C., sin embargo, en la mayoría de los casos, los restos que han llegado hasta nuestros días se corresponden con reformas y procesos de monumentalización datables en los ss. III y IV, como ocurre por ejemplo en Los Vergeles, Gabia, Daragoleja o La Zubia. Es muy posible que, hasta entonces, muchas de estas villae, principalmente las que componían ese primer cinturón periurbano, se limitasen a cumplir funciones puramente económicas, careciendo de ambientes domésticos a la altura de las exigencias de sus propietarios, que residirían en la vecina Florentia, distante unos escasos $2 \mathrm{~km}$ en el caso, por ejemplo, de la villa de Los Vergeles. Una distancia fácil de cubrir diariamente. A partir de ese momento, el cambio en las dinámicas políticas, económicas y sociales debió ir aparejado a un mayor interés por acondicionar la pars urbana de estas villae. Aunque parece ser que para entonces algunas villas ya habían dejado de funcionar, por lo que no experimentaron dicho proceso monumentalizador, es el caso por ejemplo de la de Camino de Ronda 97, una instalación abandonada en el s. III d. C. (Navas et al., 2009).

Ya a partir del s. v puede fecharse la decadencia y crisis de los asentamientos rurales que para esas fechas seguían en funcionamiento. 
Estos elementos del suburbium constituyen una muestra espacial y estadísticamente significativa en relación a la información que ha proporcionado la Arqueología Urbana en la ciudad, lo que ha permitido indagar en la concepción y organización del espacio agrario de época romana (Gutiérrez y Orfila, 2013-14).

Esta red de asentamientos rurales se ubicó en la vega fluvial del Genil, una cuenca neógena que forma el eslabón central del Pasillo Intrabético (Ocaña, 1972: 6). Se trata de una cuenca sedimentaria alargada y encajonada por un relieve 'amurallado' entre las sierras de los conjuntos bético y subbético. Contando con Sierra Elvira como único accidente pronunciado en la vega fluvial, y separada de la depresión de Antequera por el umbral triásico del pasillo de Loja, la capacidad de evacuación del río Genil se vio disminuida, lo que generó un paisaje pantanoso en la vega de Granada. Además, completa la red hídrica el agua de deshielo anual de Sierra Nevada, así como la gran cantidad de torrentes localizados en los glacis que circundan la depresión. Estas dinámicas geomorfológicas estaban más acentuadas en época romana que en la actualidad, ya que tenían lugar inundaciones periódicas, en ocasiones con un gran potencial destructivo, tal y como se aprecia en las secuencias estratigráficas de las explotaciones agropecuarias hasta ahora excavadas, donde las estructuras arquitectónicas se encuentran colmatadas con hasta 4 metros de limos, arcillas y depósitos distales de abanicos fluviales. En uno de estos sitios, Camino de Ronda n. ${ }^{0}$ 97, se han documentado técnicas constructivas específicas para aislar las estructuras y sus interiores de las acciones del agua, tal y como ha puesto de manifiesto un reciente estudio geotécnico (Navas et al., 2012). Estas inundaciones y la condición de vega fluvial propiciaron una riqueza agrícola que se tradujo en una explotación continuada de los recursos agropecuarios a lo largo de los diferentes períodos históricos. En este sentido, los suelos donde se localiza la totalidad de sitios arqueológicos hasta ahora documentados son fluvisoles calcáreos -FAO-, muy permeables, arenosos, ligeros y de textura gruesa. Se trata de suelos de alto rendimiento agrícola, que se complementan con la inmediatez

(C) Universidad de Salamanca en el acceso a los recursos hídricos por parte de los asentamientos rurales romanos.

La vega de Granada ha sido objeto de una intensa transformación territorial desde el s. XIX para mitigar los efectos destructivos de las inundaciones periódicas. Destaca en este sentido la labor realizada por Agustín de Betancourt a comienzos del s. XIX en el terreno conocido como el 'Soto de Roma' (Cuevas, 2006), de donde se sabe que proceden restos arqueológicos de época romana (Gómez-Moreno, 1888), y que pertenecía a principios del s. XIX al valido de Carlos IV, Manuel Godoy. El que más tarde fuera fundador del Cuerpo de Ingenieros, $\mathrm{Ca}$ minos, Canales y Puertos obtuvo el encargo por parte de Godoy de realizar las labores que estimase oportunas para solventar el problema de las avenidas del río Genil, que, aguas abajo de la ciudad, formaba una serie de meandros de tierras fértiles pero terriblemente expuestas a las inundaciones periódicas. Así, Betancourt hizo ańadidos/extracciones de arena en el curso del Genil, un puente de madera en Baos de Santa Fe y un sifón en el río Jotayar, así como presas provisionales en el río Genil. Ello cambió de una manera significativa el paisaje rural histórico y las dinámicas geomorfológicas de la cuenca. Por otra parte, en los últimos 50 años ha tenido lugar un cambio drástico en el paisaje, coincidiendo con la suplantación progresiva de la economía agraria tradicional de la vega por la expansión urbanística de la ciudad de Granada y los municipios de su periferia (Fig. 3). Esto ha provocado el que la mayor parte de los sitios arqueológicos que se presentan en este trabajo se conozcan por intervenciones arqueológicas de urgencia, y han convertido al área de estudio en un territorio de difícil aplicación de técnicas tradicionales de la arqueología del territorio como la prospección sistemática, o de complejo desarrollo de proyectos generales de investigación. Ello ha provocado una aparente 'ausencia' de poblamiento rural romano en la Vega Granadina que en realidad no es tal, ya que la densidad de asentamientos es notable en áreas donde se ha intervenido de forma más intensa debido a la realización de grandes proyectos urbanísticos, como el caso de la construcción del Metro Ligero de Granada entre 

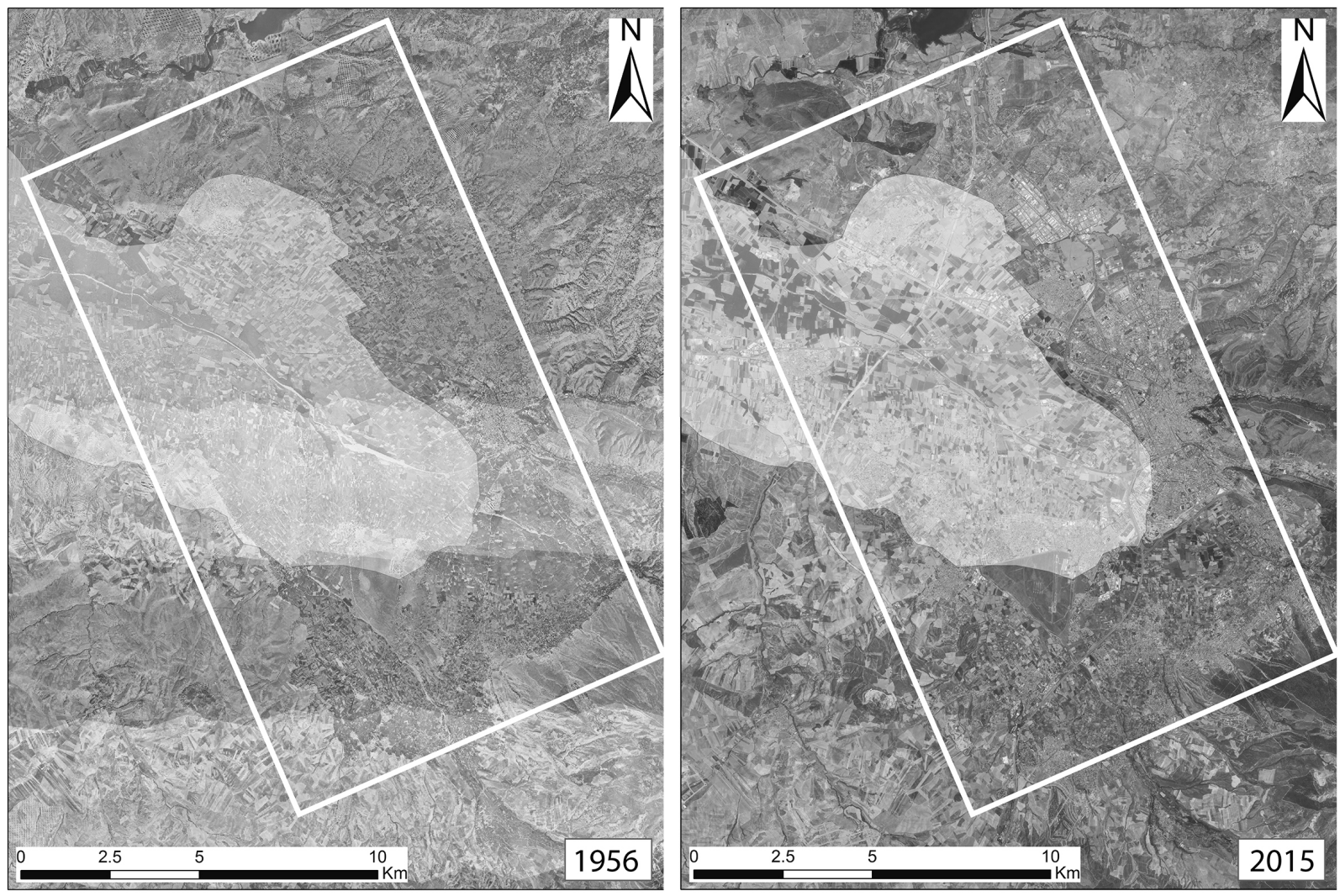

Fig. 3. Ortofotos de la Vega del Genil en 1956 y 2015; delimitación del área objeto de estudio y del área tradicionalmente inundable. Destaca la creciente urbanización del área estudiada desde los años 50 del s. XX.

Paseíllos Universitarios y la calle Recogidas. Partiendo de las limitaciones del área de estudio y los datos disponibles, este trabajo plantea el análisis arqueomorfológico como punto de partida para la comprensión del paisaje rural de época romana, una línea de investigación de largo recorrido.

\section{Las villae como reflejo del catastro: el área periurbana de Florentia Iliberritana}

Las actividades de arqueología urbana de estos últimos años en Granada han documentado una concentración especialmente significativa de villae suburbanae en la zona comprendida entre los $\mathrm{Pa}$ seíllos Universitarios y la c/ Recogidas, un área a menos de un millia passum de Florentia Iliberritana (Fig. 4). Estos lugares están situados a unas distancias muy regulares entre sí, oscilando entre los
313,79 m como distancia mínima y los 418,78 m de distancia máxima. Al comparar estas distancias con unidades de superficie de época romana, se aprecia una buena correlación con la que ocupaba un laterculus, que corresponde a $10 \times 10$ actus, cuyos lados miden $355 \mathrm{~m}$.

Tomando como base esa medida, llama la atención la cantidad de restos edificados de estas explotaciones agrarias localizados en la calle Camino de Ronda, antigua Cañada Real, y, por tanto, tradicionalmente un camino periurbano de Granada. Se ha constatado ese uso en época nazarí, momento al que corresponde la instalación de una serie de huertas situadas en sus márgenes, entre ellas las asociadas a la almunia del Alcázar Genil. Esto nos llevó al siguiente paso, comparar la orientación de los restos constructivos de estos establecimientos romanos con la de la citada calle. La orientación de dicho eje es similar a la que presentan las estructuras de Camino 

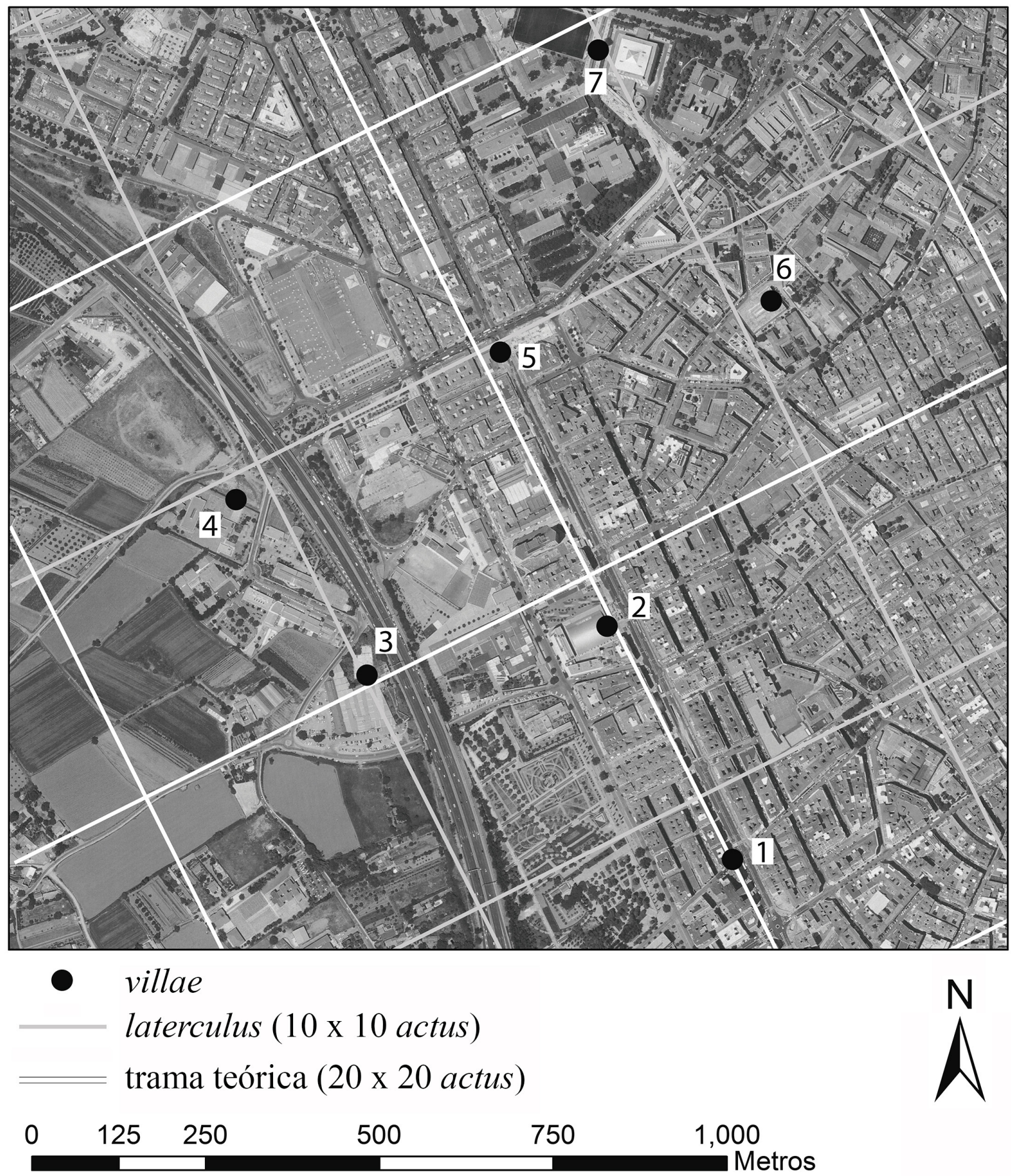

Fig. 4. Ubicación de las villae de la zona Paseíllos Universitarios-cl Recogidas en relación a un módulo de $10 \times 10$ actus: 1. Camino de Ronda-Recogidas; 2. Camino de Ronda 97; 3. Piscina Miami; 4. Instituto Generalife; 5. Camino de Ronda-Plaza Einstein; 6. La Presentación; 7. Fuentenueva. 


\begin{tabular}{|c|c|c|c|}
\hline \multirow{2}{*}{$\begin{array}{l}\text { Sitio ARQueOLÓGICO } \\
\text { Mondragones }\end{array}$} & ESTRUCTURAS DOCUMENTADAS & Cronología & BIBLIOGRAFÍA \\
\hline & $\diamond \triangleleft \cdot \cap \varnothing$ & ss. I-VII d. C. & Rodríguez et al., 2013-14 \\
\hline Armilla & $\cdot \cap \varnothing$ & \begin{tabular}{|l} 
ss. I-v d. C. \\
\end{tabular} & Gallegos, 2002 \\
\hline Laurel & $\diamond ₫ \bullet \cdot \cap \varnothing$ & ss. I-IV d. C. & inédito \\
\hline Huétor Vega & $\diamond \varsigma$ & ss. I-III d. C. & $\begin{array}{l}\text { Gómez-Moreno, 2004; García y Bellido, 1949; } \\
\text { Sánchez et al., } 2008\end{array}$ \\
\hline Híjar & $\bullet$ & ss. II-IV d. C. & Ruiz y Padial, 2004 \\
\hline Primavera & $\diamond \bowtie \bullet \cdot \cap \varnothing$ & ss. I-v d. C. & $\begin{array}{l}\text { Pérez y Toro, 1989; Fresneda et al., 1991; Burgos y } \\
\text { Risueño, } 1991\end{array}$ \\
\hline Gabia & - $\varnothing \$$ & ss. I-VI d. C. & $\begin{array}{l}\text { Cabré, 1923; Gómez-Moreno 1949; Orfila et al., } \\
\text { 2011-12 }\end{array}$ \\
\hline Camino de Ronda, 97 & $\cap \varnothing$ & ss. I-IV d. C. & Navas et al., 2009, 2010-11, 2012 \\
\hline Pago de Salazar & $\diamond \diamond \varnothing$ & ss. I-II d. C. & inédito \\
\hline Ogíjares & $\S \cdot \cap \varnothing$ & ss. I-v d. C. & Sánchez Moreno, 2010 \\
\hline Baños de Sierra Elvira & $\diamond \diamond \varnothing$ & indeterminado & Gómez-Moreno, 1888 \\
\hline Fuentenueva & - $\cap$ & en estudio & inédito \\
\hline $\begin{array}{l}\text { Camino de Ronda - } \\
\text { Plaza Einstein }\end{array}$ & $\cap$ & en estudio & inédito \\
\hline La Presentación & $\cap$ & ss. III-v d. C. & Orfila, 2011a; Román, 2004 \\
\hline $\begin{array}{l}\text { PGOU B - } 7 \text { Camino de } \\
\text { Ronda - Recogidas }\end{array}$ & $\cap$ & en estudio & $\begin{array}{l}\text { Orfila, 2011a intervenciones arqueológicas recientes } \\
\text { inéditas dirigidas por A. Rodríguez Aguilera }\end{array}$ \\
\hline IES Generalife & indeterminado; hallazgo casual & indeterminado & Orfila, 2011a \\
\hline Piscina Miami & $\cap$ hallazgo casual & indeterminado & Espinar et al., 1992 \\
\hline PGOU в-10 Caja Rural & indeterminado; hallazgo casual & indeterminado & Orfila, 2011a \\
\hline Alfar de Cartuja & $\otimes \varnothing$ & ss. I-III d. C. & $\begin{array}{l}\text { Casado et al., 1994; Serrano, 1976; Sotomayor, } \\
\text { 1966a, 1966b; Peña et al., } 2007\end{array}$ \\
\hline Plaza de los Campos & $\cap$ & ss. III-V d. C. & Casado et al., 1995 \\
\hline $\begin{array}{l}\text { PGOU B -11 Palacio de } \\
\text { Deportes }\end{array}$ & indeterminado; hallazgo casual & indeterminado & Orfila, 2011a \\
\hline Parking Escolapios & indeterminado & s. IV d. C. & Rodríguez Aguilera, 2011 \\
\hline Parque Nueva Granada & $\otimes$ & ss. II-I a. C. & Peinado et al., 2010; Ruiz et al., 2013 \\
\hline Hoyo de la Campana & $\Delta$ & ss. I-III d. C. & García Pulido, 2013 \\
\hline San Antón-Alhamar & $\cap$ & ss. II-I a. C. & Orfila, 2009; Adroher, 2007 \\
\hline Paseo de la Bomba & $\cap$ hallazgo casual & indeterminado & Orfila, 2006, 2011 \\
\hline San Juan de los Reyes & $\diamond \S \cdot$ hallazgo casual & indeterminado & Gómez-Moreno, 1888; Orfila, 2011a \\
\hline $\begin{array}{ll}\diamond & \text { pars urbo } \\
\bullet & \text { balneum } \\
\bullet & \text { torculari } \\
\$ & \text { program }\end{array}$ & $\begin{array}{l}\text { uma } \\
\text { as decorativos (musivaria, pintura }\end{array}$ & mural) & $\begin{array}{ll}\cap & \text { necrópolis rural } \\
\otimes & \text { alfares } \\
\varnothing & \text { conducciones hidráulicas } \\
\Delta & \text { explotación minera }\end{array}$ \\
\hline
\end{tabular}

FIG. 5. Relación de instalaciones agropecuarias romanas de la Vega Granadina.

de Ronda 97 y c/ Primavera, las únicas villae del área periurbana cuya planta ha sido publicada junto con Mondragones (Fresneda et al., 1993; Navas et al., 2009; Rodríguez Aguilera et al., 2013-14). La orientación a que nos referimos es la de los muros más cercanos al eje N-s, y que están, según consta en las publicaciones, respectivamente a $292,33^{\circ}$ una, y $292,52^{\circ}$ la otra. Con las cautelas necesarias ante la problemática del $\mathrm{N}$ reflejado en las publicaciones arqueológicas ${ }^{2}$, la situación nos lleva a plantear la posibilidad de que esa alineación se hubiera realizado gracias al procedimiento de la varatio, en donde la

2 Recordemos toda la problemática en cuanto a errores que suelen presentar este tipo de referencias (Le Gall, 1975; Romano, 1990; Orfila, 2012; Orfila et al., 2014). 
línea generadora de referencia bien pudo ser la de los puntos cardinales, calibrando el desvío de ese eje gracias al uso de triángulos rectángulos; en ese caso superponiendo la hipotenusa de la terna pitagórica $(5: 12: 13)$ sobre la línea $\mathrm{N}$, estando la intersección de sus catetos hacia poniente. Esta alineación identificada, además, se ajusta en gran medida a lo que podría pensarse como un ideal de planificación de una plausible división parcelaria, dado que ésta queda encajada de forma precisa en la vega de inundación que generan las montañas que envuelven la Vega Granadina, así como la red hídrica, de la que destaca el río Genil, el principal curso de agua del territorio. El Camino de Ronda podría ser, en ese caso, un antiguo camino, un kardo.

De la totalidad de asentamientos rurales localizados en el ager de Florentia Iliberritana, hay que destacar que no todas las edificaciones tienen la misma orientación, de hecho, no coinciden con las dos ya mencionadas (Figs. 6-7). En algunos de esos casos se produce una coincidencia entre esas orientaciones y las de las curvas de nivel en el lugar en donde están asentadas, facilitando así la ejecución de las obras y su adecuación al fundus. Tal es el caso de las villae de Híjar y Armilla. El resto de villae analizadas presentan otras orientaciones cuya significación debe responder a otros criterios, como Mondragones, cuyas estructuras se distribuyen de forma paralela al paleocanal del río Beiro documentado durante la excavación, quizá aprovechando este recurso en el desarrollo de actividades agropecuarias.

Es una realidad que en los yacimientos estudiados existe una equidistancia entre establecimientos, es decir, instalaciones asociadas a explotaciones agropecuarias del área periurbana de Florentia Iliberritana. Todas estas explotaciones presentan niveles estratigráficos fundacionales del s. I d. C. Estos datos permiten plantear que, de forma general, la superficie de esas plausibles fincas (praedia) rondaría los 10 actus. Hay que recordar que los fundi asignados no tienen por qué ser homogéneos (Castillo Pascual, 1996; Chouquer y Favory, 1991, 1992, 2001; López Paz, 1994). Testimonios escritos como los Gromatici Veteres (Thullin, 1913) y epigráficos como el catastro marmóreo de Arausio (Piganiol, 1962) documentan la existencia de fundi exenti o concessi, es decir, fundi segregados o respetados por la asignación, así como luci, o bosques sagrados dependientes de un templo. Sin embargo, a pesar de que la realidad arqueológica de los agri fue indudablemente más compleja que lo que la evidencia material permite intuir, pocas veces la arqueología permite llegar a ese nivel de detalle de los patrones de asentamiento. Lamentablemente, el fundus es una realidad esquiva (Ariño et al., 2004; Fiches et al., 2013).

Parece que estos edificios del ager Iliberritanus debieron ubicarse en las cercanías de alguno de los caminos surgidos de la plasmación de un catastro regular y ortogonal, pues así queda reflejado si se superpone una trama de ese hipotético trazado sobre los yacimientos hasta hoy localizados. Queda manifiesta, por una parte, la coincidencia de orientación entre algunas estructuras de las explotaciones agrarias con la del hipotético entramado general que aquí presentamos.

Las distancias entre villae junto con el módulo teórico propuesto, el laterculus, nos llevarían a un terreno adscrito a cada una de estas instalaciones de 120.000-130.000 $\mathrm{m}^{2}$. Ese entorno inmediato de las instalaciones de las fincas parece que tuvo una significación especial. En un trabajo previo se aplicó una metodología de análisis espacial destinada a comprender la significación de las instalaciones rurales en el territorio objeto de estudio, así como buscar patrones de asentamiento (Gutiérrez y Orfila, 2013-14). De esta forma, se analizaron dos variables fisiográficas, como son las cuencas visuales y la prominencia topográfica en un entorno $\mathrm{SIG}^{3}$.

3 El software empleado fue ArcGis 10 y spss 20. Para ello se construyeron tanto un modelo digital del terreno (TIN) como un modelo digital de elevaciones (DEM) a partir de puntos de cota y curvas de nivel obtenidos del Instituto Geográfico Nacional de la serie BTN 25, lo que dio como resultado un producto cartográfico a escala 1:25.000. Para los análisis de cuencas visuales y prominencia topográfica se empleó el punto de altura máxima del asentamiento. Para las cuencas visuales la altura del observador fue de $1,70 \mathrm{~m}$, mientras que para el cálculo de la prominencia topográfica de instalaciones agropecuarias se ha sumado una altura mínima estimada de su posible arquitectura $(3,5 \mathrm{~m})$. Otros detalles sobre los métodos empleados y la discusión de los resultados se encuentran publicados en detalle en Gutiérrez y Orfila, 2013-2014. 

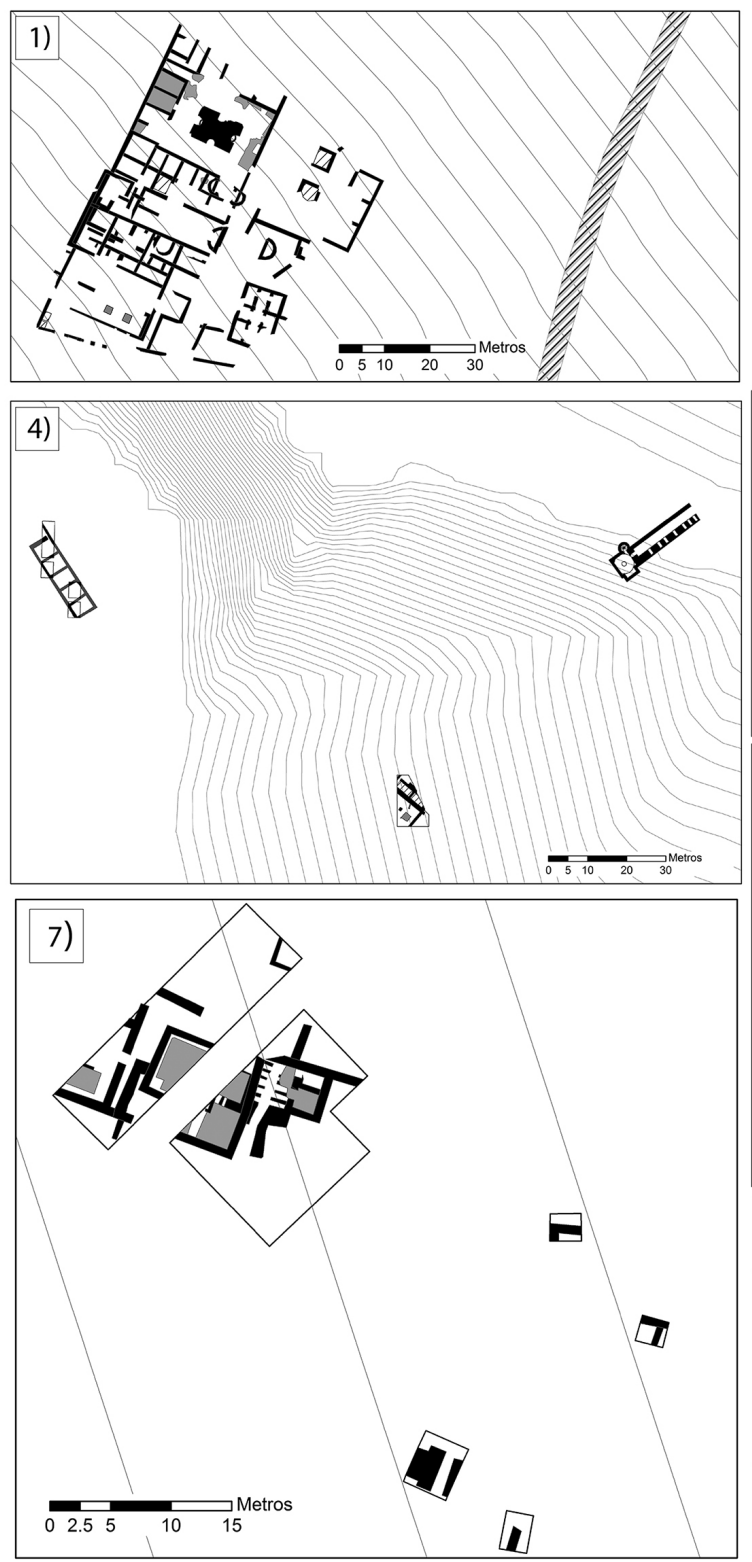
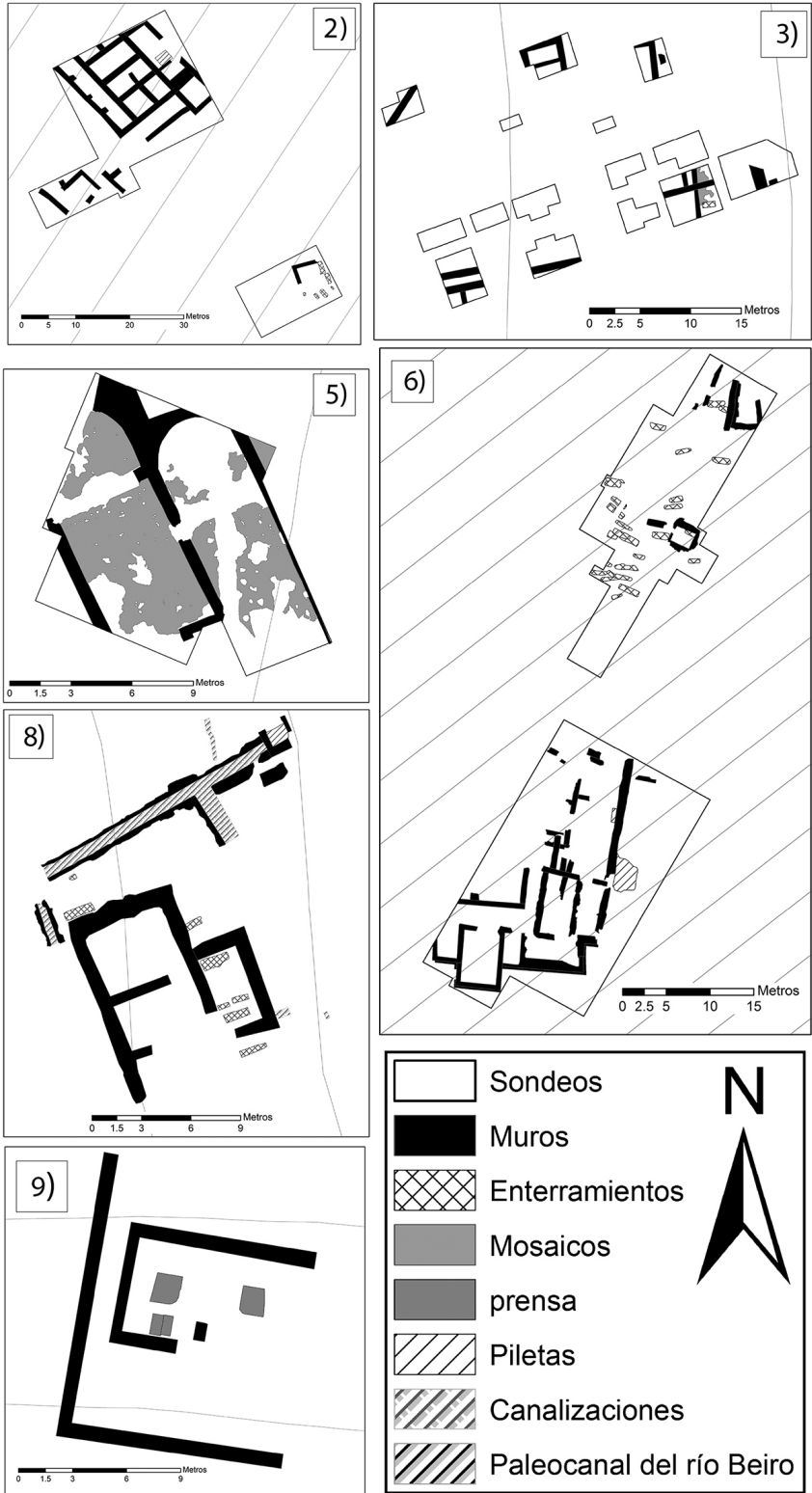

FIG. 6. Plantas de las villae iliberritanas: 1. Mondragones; 2. Armilla; 3. Laurel; 4. Gabia; 5. Primavera, 6. Ogíjares, 7. Pago de Salazar; 8. Camino de Ronda 97; 9. Hijar.

El análisis de cuencas visuales es uno de los más extendidos en Arqueología (Wheatley y Gillings, 2000). Se hizo calculando el porcentaje de visibilidad sobre la cuenca visual potencial en 4 radios $(0,5 ; 1$; 2,5 y $5 \mathrm{~km}$ ) a partir de las villae, teniendo en cuenta sus fases cronológicas. Paralelamente se repitió este proceso sobre un mismo número de ubicaciones situadas de forma aleatoria en el territorio, con el fin de realizar un análisis estadístico de contrastación, el test U de Mann-Whitney, para determinar si la visibilidad de los sitios objeto de estudio respondía a un criterio azaroso o bien los valores respondían a un patrón relacionado con la planificación previa al ubicar estas instalaciones en el territorio. Las 
villae ofrecieron unos valores muy altos con respecto a la cuenca visual potencial, especialmente en los radios de 0,5 y 1 $\mathrm{km}$ a partir de los sitios arqueológicos, que se corresponde con el entorno inmediato de las explotaciones agropecuarias. El test estadístico confirmó la existencia de una pauta territorial. Estos resultados fueron interpretados como un control visual efectivo de los fundi por parte de las villae, un es-

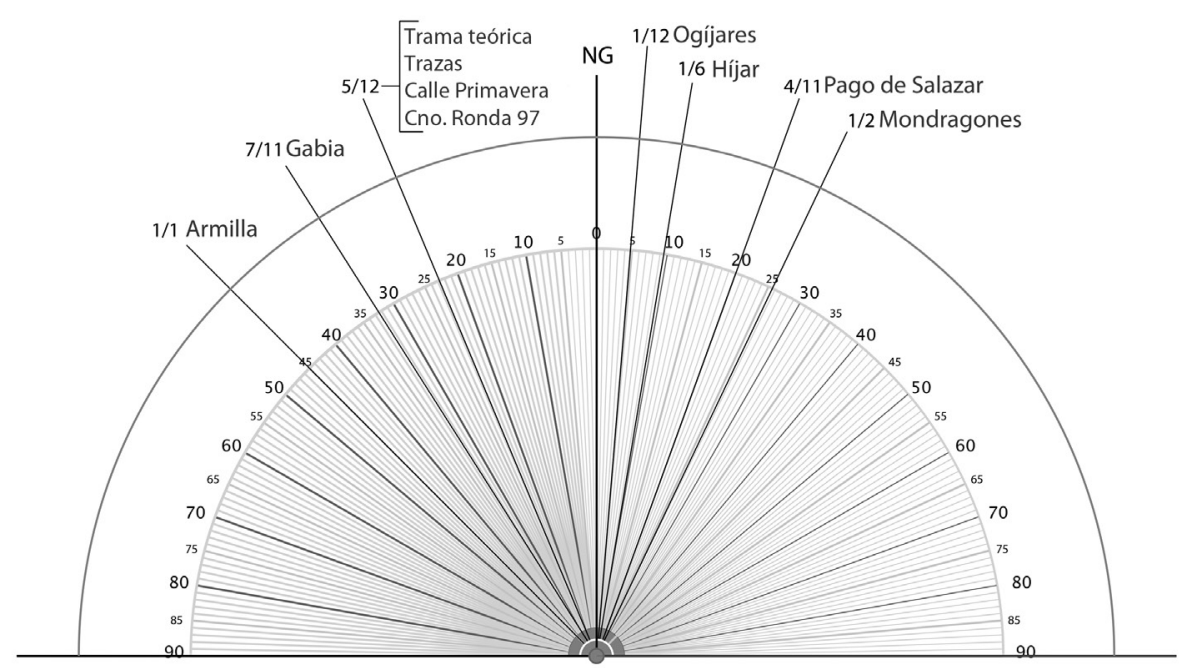
pacio donde se desarro-

Fig. 7. Orientaciones de las villae en relación a las opciones más plausibles de varatio (Orfila et al., 2014: 82 modificado).

llaban las actividades agropecuarias y donde tenían lugar las relaciones sociales de producción. Además, se constató una relación de intervisibilidad entre las instalaciones.

El segundo análisis, la prominencia topográfica, fue definido por Llobera (2001 y 2003) como una función que calculaba la diferencia en altura entre un elemento y sus alrededores, es decir, el porcentaje de localizaciones, celdas o píxeles que se encuentran por debajo del lugar estudiado en un radio concreto, lo que nos da una idea de lo destacada que es una localización, o no, con respecto al paisaje que la circunda. Concretamente se recurrió a la media tipificada desarrollada por Parcero y Fábrega (2006: 77-78)4 ${ }^{4}$, adaptándola a nuestro caso de estudio al añadir $3,5 \mathrm{~m}$ a la cota del asentamiento, como altura mínima estimada para arquitectura de las instalaciones rurales. El análisis ofreció como resultado el que las villae del espacio periurbano destacaban en el paisaje en radios de 0,5 $\mathrm{km}$ a partir de las mismas, lo que se relaciona con el módulo propuesto de 10 x 10 actus. En este sentido, las villae se constituyeron como referentes visuales en el paisaje agrario. Con la vista, la arquitectura de la uilla enmarca la impresión del observador con respecto al propietario y de éste con respecto al mundo exterior (Hales, 2003: 52-54). Se trata, pues, de

$4 \mathrm{AR}=\mathrm{AC}-\mathrm{m} / \mathrm{DT}$ un símbolo del estatus del dominus y del poder de éste (Fiz et al., 2010: 99), ya que la conexión residencia-estatus se entiende en relación con la peculiar naturaleza de la vida pública romana, que en gran medida se desarrollaba en la residencia de cada individuo (Chavarría, 2007: 94), donde mediante la división de espacios público-privado se marcan las relaciones invitados-clientes y la distinción otium/ amoenitas-negotia (Wallace-Hadrill, 1988).

$\mathrm{El}$ análisis espacial del poblamiento periurbano de Florentia Iliberritana mostró que las villae se ubicaron en las zonas más favorables del fundus, aquellas con un mayor control visual del entorno y del espacio productivo, a la par que en el lugar más elevado y destacado, tal y como sugerían los agrónomos latinos (Varrón I, 12, 1-4; Columela I, 4, 10; Palladio I, 8, 2), los cuales aconsejaban construir en un emplazamiento más elevado y seco que su entorno con un fin práctico a la par que paisajístico.

\section{La proyección del área periurbana al ager Iliberritanus}

Teniendo en cuenta los datos que aportan las villae suburbanae del ager Iliberritanus, se ha planteado un análisis sistemático, regresivo y diacrónico del territorio empleando cartografía histórica y 

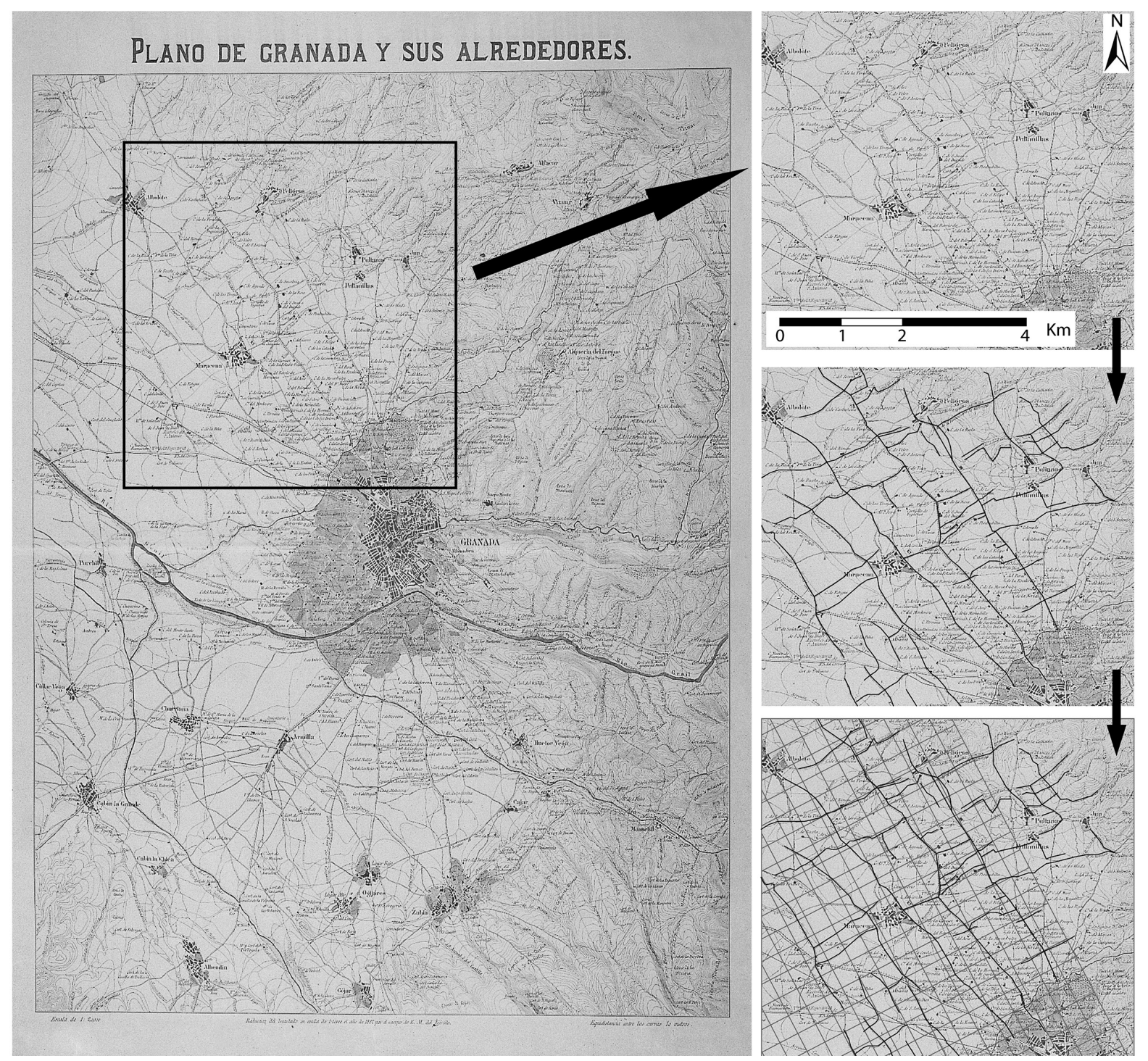

FIG. 8. Detalle de la interpretación y representación cartográfica del Plano de Granada y sus alrededores, realizado por el Cuerpo de Estado Mayor en 1887.

documentación archivística. La base cartográfica ha contado con ortofotografías del Plan Nacional de Ortofotografía Aérea (PNOA), así como el Mapa Topográfico Nacional 1: 50.000 realizado en 1931, ambos del Instituto Geográfico Nacional. Además se ha empleado el Plano de Granada y sus alrededores, realizado por el Cuerpo de Estado Mayor en 1887 (Fig. 8). El uso de estas cartografías es intencionado al ser testimonios previos a la urbanización descontrolada de la Vega Granadina desde la segunda mitad del s. xx. Finalmente, se han estudiado documentos archivísticos que muestran la organización del territorio a finales del s. $\mathrm{xv}$ y principios del xvi. Se trata de fuentes fiscales castellanas depositadas en el Archivo General de Simancas referidas a tres relaciones de alcabalas ${ }^{5}$ de las alquerías de Granada de los años 1501, 1502 y 1503, así como

5 La alcabala fue un impuesto que gravaba el comercio interior con un tipo fijo, generalmente del 10\%. En el caso de la Vega Granadina la alcabala está referida, además, a la venta de productos que tenían franqueza en la ciudad de Granada (Hernández, 1996). 

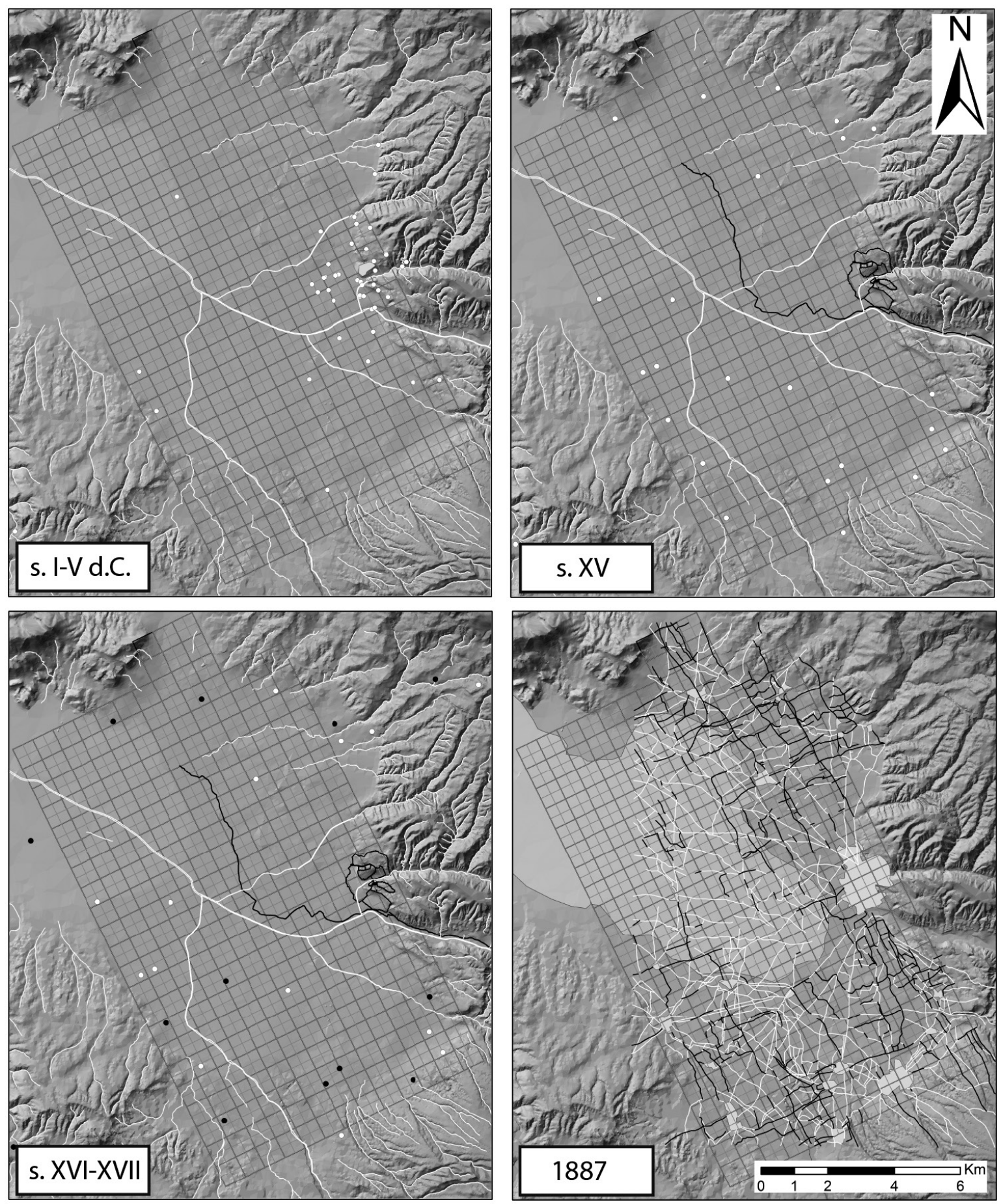

Fig. 9. Evolución del parcelario de la Vega de Granada (I): en los ss. I-V d. C.: ubicación de Florentia Iliberritana, poblamiento rural, trama teórica y orografia; en el s. XV: superposición de la Granada nazari, la Acequia Gorda del Genil y alquerías sobre orografia y trama teórica; en los ss. XVI-XVII: superposición de la ciudad de Granada y poblaciones con parroquias (negro) y anejos eclesiásticos (blanco) sobre orografía y trama teórica; en 1887: superposición de tramas ortogonales (negro) y radioconcéntricas (blanco) y núcleos de población sobre orografía y trama teórica. 
una declaración sobre los diezmos del arzobispado de Granada de 1506. Para ello nos basamos en el análisis que Hernández Benito hace de esta documentación (Hernández, 1996). Ésta resulta de gran interés, ya que, aunque se trata de una fuente post conquista, refleja la estructura territorial tardonazarí, momento en que la organización del territorio, basada en la alquería, aún no había sido alterada tras la conquista castellana. Por otra parte, la relación del cobro del diezmo evidencia la estructura territorial cristiana que, en este territorio, se mantuvo durante los ss. XVII y XVIII.

Al hacer un estudio cartográfico regresivo del territorio (Figs. 8-9) se ha documentado la existencia de tramas radiales y radioconcéntricas, que parten de municipios actuales que tienen su origen en la alquería medieval, o bien actúan como elemento de conexión entre las mismas. Esto nos proporciona una datación relativa más antigua a una serie de trazas que mantienen la misma orientación que algunas de las villae iliberritanas conocidas hasta hoy, al anular dicho parcelario o bien integrarlo en algunos casos. Esta trama ortogonal antigua ha ido desapareciendo paralelamente a la urbanización del territorio. La conservación de trazas es especialmente notable en las áreas al $\mathrm{N}$, entre la actual ciudad de Granada, Albolote y Alfacar, así como al $s$ de la ciudad, entre Las Gabias y Monachil. Por el contrario, al o, coincidiendo con las áreas de inundación periódica y regadíos del Genil, hay un menor número de trazas debido a la fuerte transformación provocada por las dinámicas geomorfológicas y el uso intensivo del suelo. La orientación de este parcelario (Figs. 9-10) tiene una buena correlación con una malla teórica de módulo de 20 x 20 actus, con subdivisiones internas de 10 x 10 actus. Sus límites coinciden con la delimitación natural de la cuenca sedimentaria, al presentar un trazado y orientación general perfectamente adaptados a las dimensiones, las pendientes y al drenaje natural al recibir las aguas torrenciales de los glacis que circundan la vega fluvial.

La existencia de este parcelario se documenta en momentos previos a los ss. XIX-Xx (Figs. 9-10). Para el territorio objeto de estudio apenas contamos con fuentes cartográficas anteriores a la conquista castellana del área. Por ello se hace imprescindible el empleo de fuentes escritas, como las de carácter fiscal anteriormente mencionadas. Si las observamos desde un punto de vista territorial, la localización de las alquerías tardonazaríes parece guardar una estrecha relación con la trama teórica de época romana que proponemos, al ubicarse la mayoría de éstas en cruces de caminos teóricos, bien de centurias, bien de laterculi. Lo mismo sucede con las parroquias y anejos de principios del s. Xvi. Cabe recordar que en gran número de estos municipios se han identificado villae (Gabia, Híjar, Ogíjares, La Zubia, Huétor Vega, etc.). Por otra parte, sorprende la aparente relación de algunas acequias o cursos de agua tradicionalmente considerados medievales, si bien algunos autores dudan de su cronología (García, 2013), como es la Acequia Gorda del Genil, la cual mantiene, en líneas generales, la misma orientación que la trama teórica y en algunos casos incluso se imbrica con ella.

El ager Iliberritanus apenas conserva documentos epigráficos de cronología romana relativos a la red de calzadas o la organización del territorio, más allá del discutido terminus de Sierra Elvira (CIL II suppl., 5510; Pastor y Mendoza, 1987: 50-52 ILPGr 18). Este epígrafe, datado en época de Domiciano, ha sido tradicionalmente interpretado como un marcador territorial, si bien su lectura es críptica y su interpretación controvertida ${ }^{6}$. El parcelario identificado se extiende hasta Sierra Elvira, lugar de hallazgo del posible terminus. Otro testimonio es el epígrafe localizado en la Venta de los Diablos de Nívar (CIL II, 5064). El texto hace mención a la existencia de una statio portorium de tasación de mercancías en esta zona (Pastor y Mendoza, 1987: 153-155), que estaría revelando la existencia de una frontera económica (Orfila, 2011a: 142) y ¿quizá el límite del territorium del ager Iliberritanus?

Ante la ausencia de otras evidencias, la ubicación delas villaese convierte en un testimonio indirecto de la organización del territorio. Al extender la malla teórica a la totalidad de la Vega Granadina, se aprecia

6 Una revisión historiográfica acerca de la interpretación del pedestal puede encontrarse en Ariño et al., 2004: 23-28. 

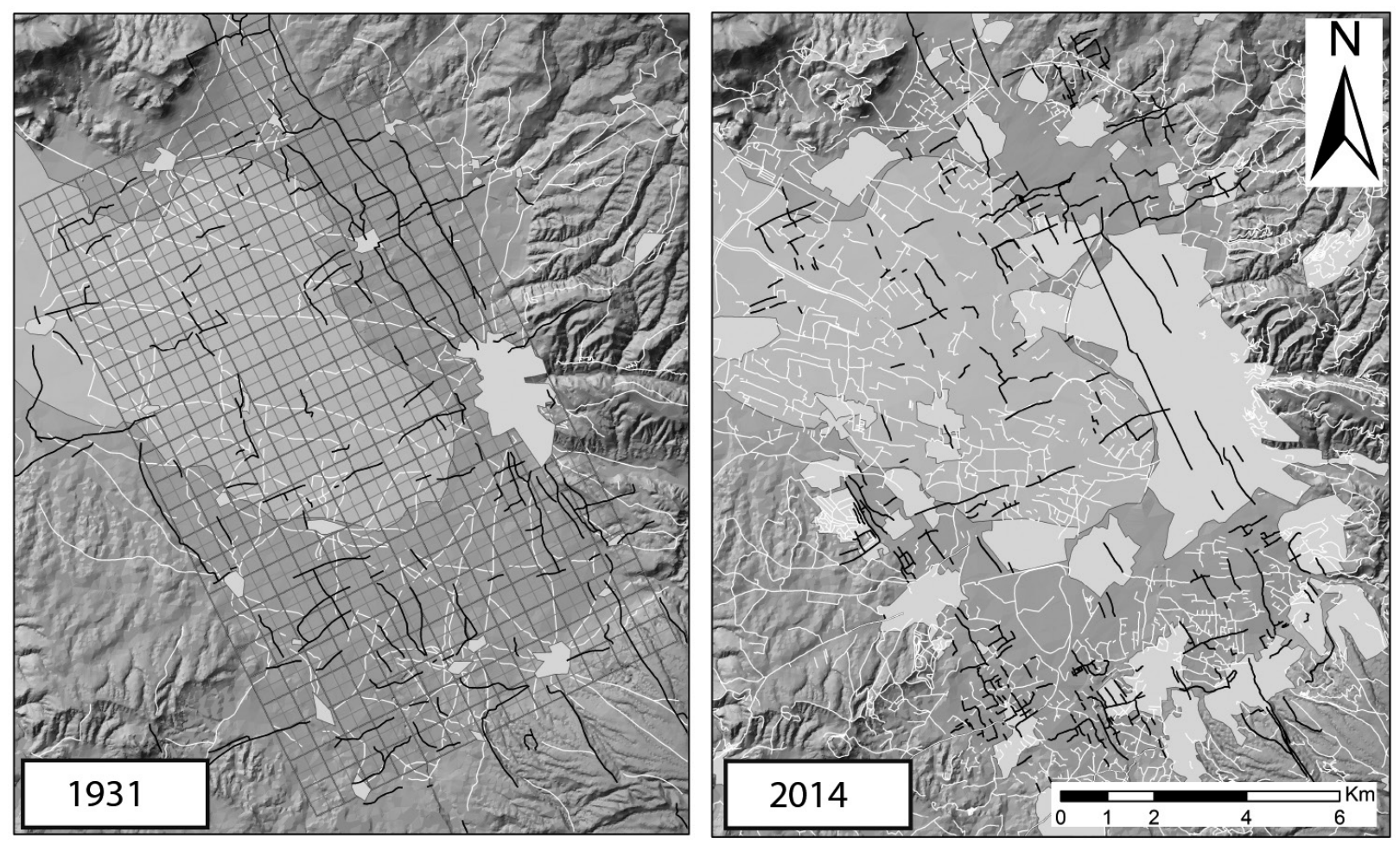

Fig. 10. Evolución del parcelario de la Vega de Granada (II) en 1931 y 2015: superposición de tramas ortogonales (negro) y radioconcéntricas (blanco) y núcleos de población sobre orografía y trama teórica.

una relación de ésta con el poblamiento rural romano, al ubicarse las instalaciones agropecuarias en los cruces de centurias y laterculi y tener, en ocasiones, la misma orientación que la trama teórica y el parcelario.

Se ha medido la proximidad de instalaciones agropecuarias tanto a los límites de las centuriae como a los de laterculi, y se ha seguido el mismo procedimiento con un número de puntos aleatorios igual al de villae identificadas (21), así como con las alquerías nazaríes. Los histogramas de frecuencias de cercanía a los ejes de centurias y laterculi (Fig. 12) muestran ciertos patrones. Por una parte, las villae suelen localizarse a muy poca distancia de los ejes, pero especialmente en el caso del laterculus, como reflejan las medias y la curva de normalidad. Por el contrario, los histogramas relativos a la ubicación de los puntos aleatorios muestran una dispersión muy heterogénea de los datos y valores de media superiores, que alejan estas ubicaciones de los caminos teóricos. Finalmente, si atendemos a los valores de media, la distribución de las alquerías nazaríes es similar a las villae en relación a la centuria, si bien para la distancia al laterculus la media muestra una gran similitud en relación a los puntos aleatorios. Se ha empleado el test U de Mann-Whitney (Fig. 12) con el fin de contrastar si la diferencia entre las medias de los conjuntos de datos es estadísticamente significativa. Con esta premisa se ha contrastado la distancia de villae a los ejes con la de puntos aleatorios, para determinar si existe una relación estadística entre la ubicación de éstas y la trama teórica, y por tanto con los caminos. Por otra parte, se ha realizado el mismo test referido a villae y alquerías nazaríes, para contrastar en qué medida hubo, o no, una continuidad de la estructura territorial romana en la Edad Media. Dicho test y los histogramas de frecuencias manifiestan la estrecha relación entre la ubicación de las villae y la trama teórica, al estar los valores de significación por debajo del límite de confianza $(0,05)$ para el caso del laterculus. El test u de Mann-Whitney refleja una continuidad de la 

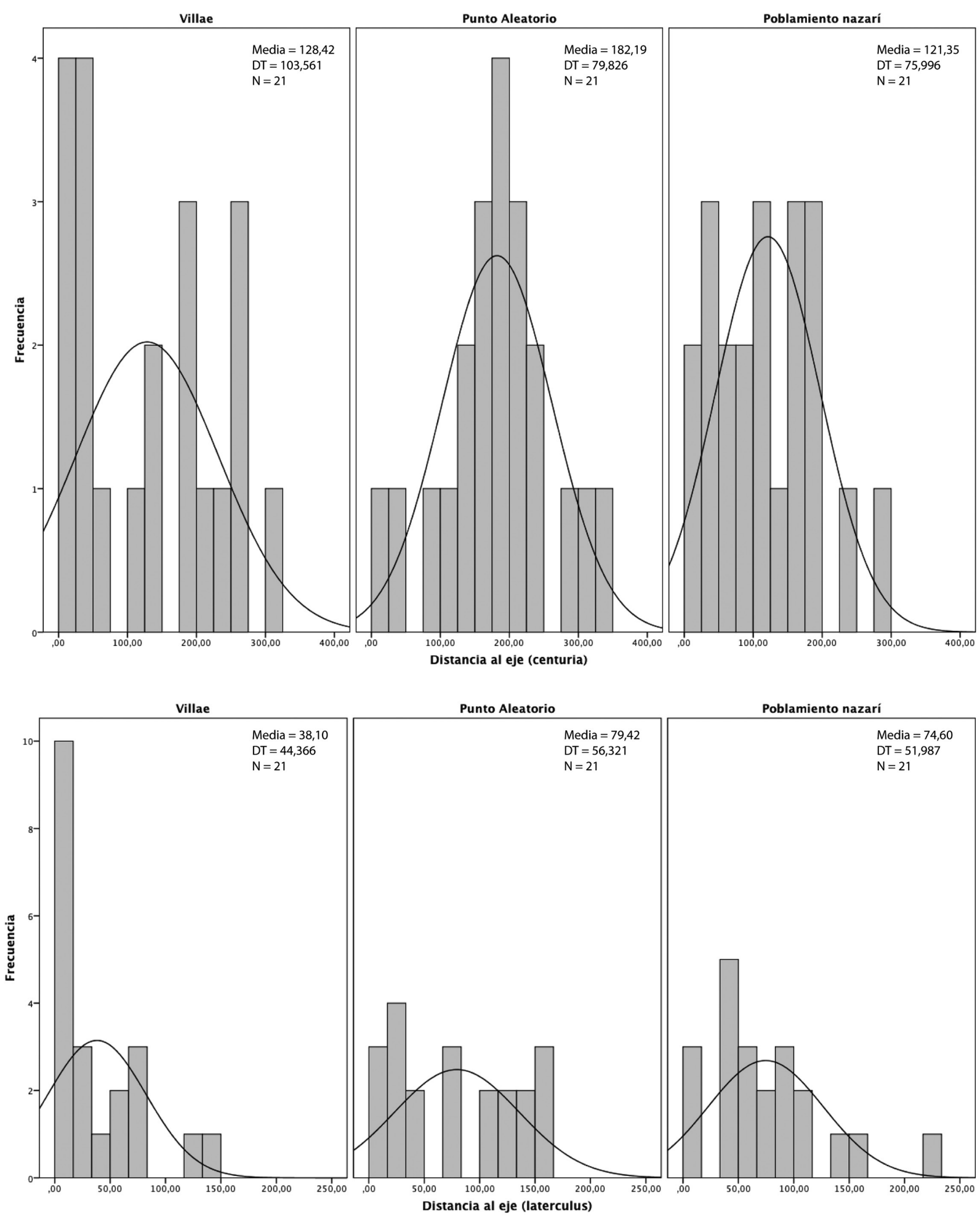

Fig. 11. Histogramas de frecuencias de distancia de villae, alquerías nazaries y puntos aleatorios a los ejes de centuriae $y$ laterculi. 
centuria en la estructura territorial tardonazarí frente al laterculus, lo que nos indica que pudo haber una pérdida progresiva de las divisiones internas frente a los ejes principales, donde se habrían ubicado las alquerías. Esta relación también se aprecia en los valores de media de los histogramas de frecuencia de las alquerías, donde la media para la centuria $(121,35)$ es muy próxima a la del poblamiento rural romano $(128,42)$, frente a la media del laterculus $(74,60)$ que se asemeja a la media de puntos aleatorios $(79,42)$.

El conjunto de análisis hasta ahora desarrollados (arqueografía, arqueomorfología, análisis espacial y estadístico) podría estar revelando la existencia de un territorio centuriado de época romana que pertenecería al Municipium Florentinum Iliberritanum. La ciudad presenta una situación periférica, y a la vez central, con respecto al conjunto del parcelario identificado. En este sentido, la relación morfológica entre la estructura urbana y el territorio difiere del modelo teórico de la ratio pulcherrima como ocurre en tantos lugares, tal y como indican los gromatici (Hyginio Gromático Th, 142.145), situación que fue habitual. De forma general las instalaciones rurales de este territorio comienzan a funcionar unitariamente a mediados del s. I d. C. (Sánchez et al., 2009: 109-111), por tanto, necesariamente esta organización del territorio, concebida y planificada, tuvo que realizarse antes de la construcción de las villae que mantienen la misma orientación. Cabe recordar la temprana municipalización de Florentia Iliberritana anteriormente referida en época césaro-augústea (Orfila, 2011a).

La presencia de un posible parcelario en la zona de estudio conllevaría una serie de procesos de

\section{A. VILLAE Y PUNTOS ALEATORIOS}

RANGOS

\begin{tabular}{|c|l|c|c|c|}
\hline \multicolumn{2}{|c|}{ Tipo } & N & $\begin{array}{c}\text { Rango } \\
\text { promedio }\end{array}$ & $\begin{array}{c}\text { Suma } \\
\text { de rangos }\end{array}$ \\
\hline \multirow{2}{*}{$\begin{array}{c}\text { Distancia al eje } \\
\text { (centuria) }\end{array}$} & villae & 21 & 18,57 & 390,00 \\
\cline { 2 - 5 } & punto aleatorio & 21 & 24,43 & 513,00 \\
\hline $\begin{array}{c}\text { Distancia al eje } \\
\text { (laterculus) }\end{array}$ & villae & 21 & 16,90 & 355,00 \\
\cline { 2 - 5 } & punto aleatorio & 21 & 26,10 & 548,00 \\
\hline
\end{tabular}

Estadísticos DE CONTRASTE

\begin{tabular}{|l|c|c|}
\cline { 2 - 3 } \multicolumn{1}{c|}{} & \multicolumn{1}{c|}{$\begin{array}{c}\text { Distancia al eje } \\
\text { (centuria) }\end{array}$} & $\begin{array}{c}\text { Distancia al eje } \\
\text { (laterculus) }\end{array}$ \\
\hline U de Mann-Whitney & 159,000 & 124,000 \\
\hline w de Wilcoxon & 390,000 & 355,000 \\
\hline Z & $-1,547$ & $-2,433$ \\
\hline Sig. asintót. (bilateral) &, 122 &, 015 \\
\hline
\end{tabular}

\section{B. VILLAE Y POBLAMIENTO NAZARÍ}

RANGOS

\begin{tabular}{|l|l|c|c|c|}
\hline \multicolumn{2}{|c|}{ Tipo } & N & $\begin{array}{c}\text { Rango } \\
\text { promedio }\end{array}$ & $\begin{array}{c}\text { Suma } \\
\text { de rangos }\end{array}$ \\
\hline \multirow{2}{*}{$\begin{array}{l}\text { distancia al eje } \\
\text { (centuria) }\end{array}$} & villae & 21 & 21,71 & 456,00 \\
\cline { 2 - 5 } $\begin{array}{l}\text { distancia al eje } \\
\text { (laterculus) }\end{array}$ & poblamiento nazarí & 21 & 21,29 & 447,00 \\
\cline { 2 - 5 } & villae & 21 & 16,33 & 343,00 \\
\hline
\end{tabular}

Estadísticos DE CONTRAste

\begin{tabular}{|l|c|c|}
\cline { 2 - 3 } \multicolumn{1}{c|}{} & \multicolumn{1}{c|}{$\begin{array}{c}\text { Distancia al eje } \\
\text { (centuria) }\end{array}$} & $\begin{array}{c}\text { Distancia al eje } \\
\text { (laterculus) }\end{array}$ \\
\hline u de Mann-Whitney & 216,000 & 112,000 \\
\hline w de Wilcoxon & 447,000 & 343,000 \\
\hline z &,- 113 & $-2,733$ \\
\hline Sig. asintót. (bilateral) &, 910 &, 006 \\
\hline
\end{tabular}

FIG. 12. Test U de Mann-Whitney para rangos de distancia de villae, asentamientos nazaries y puntos aleatorios a los ejes de centuriae $y$ laterculi. sistematización del campo, entre los cuales debió de realizarse una desecación del entorno. Quizás la existencia de un catastro resolvería la cuestión de por qué hay villae en plena zona de afección de las inundaciones periódicas. El empleo de canales asociados a la parcelación para la derivación de agua sobrante del medio natural fue una práctica habitual en este tipo de obras, que hasta el momento no ha sido detectada en la zona de estudio. De hecho, la lex fundacional de Urso describe un paisaje con 
alusión a limites, decumani y fosas de drenaje (Ariño et al., 2004: 63).

\section{Conclusiones}

El análisis territorial de la Vega de Granada permite proponer la existencia de una posible centuriación cuyo módulo sería de 20 x 20 actus, con divisiones internas de $10 \times 10$ actus asociada a Florentia Iliberritana. Para su identificación han sido de gran importancia los datos inferidos de la ubicación y orientación de villae e instalaciones agropecuarias. La inserción del poblamiento rural en la red de calzadas ya es una cuestión recogida en las fuentes escritas, que muestran una preocupación por el cuidado de las viae vicinales, elementos de conexión entre la ciudad y su territorio (Tabula Heraclensis; Ley de las XII Tablas; Ulpiano, Dig., XLIII, 8, 2, 21; Catón, De agr., II, 4; Higinio, 83, 18; Sículo Flaco, 146, 1; Frontino, De contr. agr., 38, 1; Lex Coloniae Iuliae Genetivae Urso; Columela, De agr. I, 2, 1).

Dentro del grado de variabilidad en la morfología de los paisajes agrarios centuriados, los resultados obtenidos en el ager Iliberritanus presentan una serie de pautas diferenciales con respecto a otras zonas donde se han identificado parcelarios de cronología romana. En este sentido, cabe recordar que la sortitio de Ilici muestra un reparto de 130 ingera a 10 colonos. Estas propiedades registradas en la sortitio reflejan fundi de 13 iugera de extensión por cada uno de los veteranos asentados en la colonia (Mayer y Olesti, 2001; Guillaumin, 2002). En este sentido, la densidad de una villa por laterculus identificada en Florentia Iliberritana que en este trabajo se propone como dimensión para los fundus, especialmente aquellos del área periurbana, estaría creando parcelas de una superficie notablemente mayor de la documentada en el caso ilicitano.

Se manifiesta el amplio abanico de variables que ofrecen estas instalaciones susceptibles de ser integradas en la metodología de análisis arqueomorfológico del territorio, situación hasta ahora pocas veces desarrollada desde un punto de vista sistemático en el estudio de las parcelaciones romanas. En la lectura de este escrito se ha podido apreciar que para llegar a estas conclusiones nos hemos basado en la aplicación de una serie de parámetros, unos procedentes de las indicaciones de los propios agrimensores romanos, otros producto de deducciones a través de bienes arqueológicos. Muchos de ellos han sido expuestos en otras obras, y por otros investigadores. Aquí hemos querido avanzar al incluir nuevos criterios, como son entender la orientación de las instalaciones agropecuarias existentes en el territorio y analizar su ubicación no sólo en el espacio, sino a través de la distancia entre las mismas. La prominencia topográfica y cuencas visuales de estas localizaciones nos ha permitido igualmente entender la inserción del poblamiento rural en el ager Iliberritanus. No obstante, somos conscientes de que en el futuro esta línea de investigación llevará a que otros nuevos parámetros deban también tenerse en cuenta a la hora de analizar un territorio rural romano como el de Florentia Iliberritana. Estos nuevos parámetros ayudarán a la mejor comprensión de un territorio tan urbanizado y tan agrario como la Bética, en el que, sin embargo, hasta el momento se han identificado pocos parcelarios rurales ${ }^{7}$.

\section{Bibliografía}

Adroher, A. M. (2007): "Granada desde sus inicios hasta el fin de la época ibérica”, Boletín de la Real Academia de Bellas Artes de Nuestra Señora de las Angustias, 14, pp. 15-48.

Adserias, M.; Pociña, C. A., y Remolà, J. A. (2000): "L’hàbitat suburbà portuari de l'antiga Tàrraco. Excavacions al sector afectat pel peri 2 (Jaume I-Tabacalera)". En Ruiz De Arbulo, J. (ed.): Tàrraco 99 arqueologia d'una capital provincial romana (Tarragona, 1999). Documents d'Arqueologia Classica, 3. Tarragona, pp. 137-154.

ANDRÉs, G. (1998): "Seguimientos arqueológicos en varios puntos del casco antiguo de la ciudad de Calahorra", Estrato, 9, pp. 9-44.

Ariño, E.; Gurt, J. M.; Lanuza, A. y Palet, J. M. (2004): El pasado presente. Arqueología de los paisajes en la Hispania Romana. Salamanca: EUSAL.

7 Orfila, M.: "Las villae agropecuarias". En Hidalgo, R. (ed.): Las villas romanas de la Bética. Sevilla, en prensa. 
Blume, F.; Lachmann, K.; Mommsen, Th. y Rudorff, A. (1848-1852): Gromati Veteres. Die Schriften der römischen Feldemesser. Berlin, vols. I-II.

Burgos, A. y Risueño, B. (1991): "Excavación de urgencia en el solar situado en la c/ Primavera n. ${ }^{\circ} 25$ de Granada”. En Arqueológico de Andalucía 1989. Sevilla, t. III, pp. 202-204.

CABRÉ, J. (1923): Monumento cristiano bizantino de Gabia la Grande (Granada). Memorias de la Junta Superior de Excavaciones y Antigüedades, 55. Madrid.

Campbell, J. B. (2000): The writings of the Roman Land surveyors. Introduction, Text, Translation and Commentary. Journal of Roman Studies, Monograph 9. London.

Carder, J. N. (1978): Art Historial Problems of a Roman Land Surveying Manuscript: The Codex Arcerianus A, Wolfenbüttel. New York-London: Garland Publishing.

Casado, P . J.; Alemán, I.; Moreno, E. y Riquelme, J. A. (1995): "Excavación de urgencia realizada en los solares n. ${ }^{\text {os }} 17$ y 19 de la calle Ángel Ganivet y n.o 3 de la calle de San Matías (Barrio de San Matías, Granada)". En Arqueológico de Andalucial1992. Sevilla, t. III, pp. 310-318.

Casado, P .; Burgos, A.; Orfila, M.; Alcaraz, F.; Fernández García, M. I.; Cassinello, S.; Cevidades, S.; Guerrero, G.; Murga, J. y Ruiz Torres, S. (1994): "Intervención arqueológica de urgencia en el alfar romano de Cartuja (Granada)". En Anuario Arqueológico de Andalucía 1994. Sevilla, t. III, pp. 129-139.

Castillo, M. J. (1996): Espacio de orden: El modelo gromático-romano de ordenación del territorio. Logroño: Univ. de La Rioja.

Chavarría, A. (2007): El final de las villas en Hispania (ss. IV-VIII). Bibliothèque de l'Antiquité Tardive, 7. Brepols: Turnhout.

Chevallier, R. (1974): "Cité et territoire. Solutions romaines aux problèmes de l'organisation de l'espace. Problematique 1948-1973". En Temporini, H. y HAASE, W. (eds.): Aufstieg und Niedergang der römischen Welt: Geschichte und Kultur Roms im Spiegel der Neuer Foschungs II-1. Berlin, pp. 649-788.

Chic, G. (2000): "Economía en la zona meridional en época romana”. En Salvador, F. (ed.): Hispania meridional durante la Antigüedad. Jaén, pp. 95-145.

Chouquer, G.; Clavel-Leveque, M. y Favory, F. (1983): "Catastri romani e sistematizacione dei paesaggi rurali antichi”. En AA. vv.: Misurare la terra: centuriazione e coloni nel mondo romano. Modena: Ed. Panini, pp. 39-49.
Chouquer, G.; Clavel-Leveque, M.; Favory, F. y VALLAT J.-P. (1987): Structures agraires en Italie centro-méridionale. Cadastres et paysages ruraux. Roma.

Chouquer, G. y Favory F. (1991): Les paysages de l'Antiquité. Terres et cadastres de l'Occident romain. Colection des Hésperides. Paris: Édit. Errance.

Chouquer, G. y Favory, F. (1992): Les arpenteurs romains. Théorie et pratique. Paris.

Chouquer, G. y Favory F. (2001): L'arpentage romain. Histoire des Textes-Droit-Techniques. Paris: édit. Errance.

Cuevas, J. (2006): El Real Sitio Soto de Roma. Colección Documental. Colección General. Granada.

De Rossi, G. M. (1979): Bovillae. En Forma Italiae, I, p. 15.

Espinar, M.; Quesada, J. J. y Amezcua Pretel, J. (1992): "Materiales romanos, visigodos y árabes en la Autovía de Circunvalación de Granada. Aportaciones a la Arqueología y Cultura Material". En In memoriam Juliana Cabrera Moreno. Granada: UGR, pp. 103-116.

Fiches, J. L.; Plana, R. y Revilla, V. (2013): Paysages ruraux et territoires dans les cités de l'Occident romain. Ager, Ix. Collection Mondes Anciens. Montpellier: Presses Universitaires de La Méditerranée.

Fiz, I.; López, J.; Prevosti, M. y Abela, J. (2010): “In conspectu prope totius urbis: la aplicación de diferentes métodos de análisis de visibilidad al paisaje del ager Tarraconensis", Cuadernos de Prehistoria y Arqueología Univ. de Granada, 20, pp. 97-122.

Fresneda, E.; Toro, I.; Peña, J. M.; Gómez, R. y López, M. (1993): "Excavación arqueológica de emergencia en la villa romana de la c/ Primavera (Granada)". En Anuario Arqueológico de Andalucía 1991. Sevilla, t. III, pp. 149-156.

Gallegos, L. (2002): "La villa y la necrópolis tardorromana de Armilla (Granada)". En Anuario Arqueológico de Andalucía 1999. Sevilla, t. III, pp. 251-258.

García y Bellido, A. (1949): Esculturas romanas de España y Portugal. Madrid: CSIC.

García Pulido, L. (2013): El territorio de la Alhambra: evolución de un paisaje cultural remarcable. Granada: Patronato de la Alhambra y Generalife.

Gómez-Moreno, M. (1988 ed. facs. [1888]): Monumentos romanos y visigóticos en Granada. Granada: UGR.

Gómez-Moreno, M. (1949): Misceláneas de historia, arte y arqueología, Primera Serie. La Antigüedad. Madrid.

Guillaumin, J. Y. (2002): "Note sur le document cadastral romain découvert à la Alcudia (Elche, province d'Alicante)", Dialogues d'Histoire Ancienne, 28 (1), pp. 113-134. 
Guillaumin, J. Y. (2005): Les arpenteurs romains. Hygin le Gromatique, Frontin. Paris.

Gurt, J. M.; Lanuza, A. y Palet, J. M. (1996): "Revisión del catastro romano de Ilici (Elche)", Pyrenae, 27, pp. 215-226.

Gutiérrez Rodríguez, M. y Orfila, M. (2013-14): "El área periurbana de Florentia Iliberritana, aproximación a su configuración espacial”, Romula, 12-13, pp. 445-474.

GuY, M. (1993): "Les orientations des parcellaires quadrillés", Revue Archéologique de Narbonnaise, 26, pp. 57-68.

Hales, S. (2003): The Roman House and Social Identity. Cambridge.

Hernández Benito, P. (1996): “Alcábalas y diezmos. Economía y estructura del poblamiento en la vega de Granada a través de las fuentes fiscales castellanas (1501-1506)", Arqueología y Territorio Medieval, 3, pp. 65-90.

Le Gall, J. (1975): "Les Romains et l'orientation solaire", Mélanges de l'École Française de Rome, Antiquité, 87, pp. 287-320.

Llobera, M. (2001): "Building past landscape perception. Understanding topographic prominence", Journal of Archaeological Science, 25, pp. 1005-1014.

Llobera, M. (2003): "Extending GIs-based visual analysis: the concept of visualscapes", International Journal of Geographical Information Science, 17 (1), pp. 25-48.

López Paz, P. (1994): La ciudad romana ideal. I. El Territorio. En Pereira, G. (ed.): La economía política de los romanos. I. Santiago de Compostela.

Marín DíAz, P. (2011): "Una aproximación a la musivaria tardoantigua en Iliberris. Los mosaicos de la villa de los Vergeles (Granada)", Arqueologi@y Territorio, 8, pp. 173-186.

Mayer M. y Olesti, O. (2001): "La sortio de Ilici: del documento epigráfico al paisaje histórico”, Dialogues d'Histoire Ancienne, 27 (1), pp. 109-130.

Moatti, C. (1993): Archives et partage de la terre dans le monde Romain (II siècle avant - $f^{r}$ siècle après J.C.). Collection de l'École Française de Rome, 173. Roma.

Navas, E.; Garrido, A., Román, J. M. y Esquivel, J. A. (2009): "Una nueva villa romana en el centro de Granada: estudio preliminar", Antiquitas, 21, pp. 97-113.

Navas, E.; Garrido, A.; Román, J. M. y Esquivel, J. A. (2010-2011): "La necrópolis tardorromana de la antigua estación de autobuses de Granada", Anales de Arqueología Cordobesa, 21-22, pp. 221-240.
Navas, E.; Garrido, A.; Román, J. M. y Esquivel, J. A. (2012): "Geotechnical and metric engineering applied to building of a Roman villa in the Vega of Granada (Spain)", Mediterranean Archaeology and Archaeometry, 12 (1), pp. 31-41.

OrfiLA, M. (2011a): Florentia Iliberritana. La ciudad de Granada en época romana. Granada: UGR.

Orfila, M. (2011-12): "Un posible sistema para orientar estructuras de trazado ortogonal en época clásica. El caso de Pollentia (Mallorca, España)", GEOGRAPHIA ANTIQUA, XX-XXI, pp. 123-136.

Orfila, M.; Chávez, M. E. y SÁnchez, E. (eds.) (2014): La orientación de las estructuras ortogonales de nueva planta en época romana. De la varatio y sus variaciones. Granada: UGR.

Orfila, M.; Maeso, C.; SÁnchez López, E. y MoreNo, S. (2011-2012): "La ocupación rural de la Vega de Granada: villas, aceite y vino". En Noguera, J. M. y Antolinos, J. A. (coords.): De vino et oleo Hispaniae. Áreas de producción y procesos tecnológicos del vino y el aceite en la Hispania romana. Anales de Prehistoria y Arqueología, 27-28. Madrid, pp. 421-429.

Palet, J. M. y Orengo, H. A. (2010): Les centuriacions de l'ager tarraconensis: organització $i$ concepcions de l'espai. En Prevosti, M. y Guitart i Duran, J. (eds.): Ager Tarraconensis. I. Col. Documenta, 16. Tarragona, pp. 121-154.

Palet, J. M.; Orengo, H. A. y Riera, S. (2010): “Centuriación del territorio y modelación del paisaje en los llanos litorales de Barcino (Barcelona) y Tarraco (Tarragona): Una investigación interdisciplinar a través de la integración de datos arqueomorfológicos y paleoambientales", Agri Centuriati, 7, pp. 113-129.

Parcero, C. y Fábrega, P. (2006): "Diseño metodológico para el análisis locacional de asentamientos a través de un sig de base raster". En Grau, I. (ed.): La aplicación de los SIG en la Arqueología del Paisaje. Alicante, pp. 69-90.

Pastor, M. y Mendoza, A. (1987): Inscripciones latinas de la provincia de Granada. Granada.

Peinado, M. V.; Ruiz Montes, P.; Ayerbe, J. L.; Gómez Timón, P.; García Consuegra, J. M.; Morcillo, F. J.; Rodríguez Aguilera, J.; Serrano, B.; Moreno, M.; Marcon, C.; López Hernández, R.; Jiménez de Cisneros, M. y Gómez Fernández, A. (2010): "Parque Nueva Granada: un nuevo asentamiento productivo romano-republicano en la Vega oriental de Granada", Ex Officina Hispanica, 2, pp. 35- 36. 
Peña, P.; Teixidó, T.; Carmona, E. y Orfila, M. (2007): "Prospecciones geofísicas en los hornos romanos de Cartuja (Granada). Un ejemplo para obtener información a priori”, Arqueología y Territorio, 4, pp. 217-232.

Pérez, C. y Toro, I. (1989): "Intervención arqueológica de urgencia en c/ Primavera, 22 (Los Vergeles, Granada)". En Anuario Arqueológico de Andalucía 1989, t. III, pp. 228-232.

Piganiol, A. (1962): Les documents cadastraux de la colonie romaine d'Orange. Paris.

Prieto, A. (2002): "Espacio social y organización territorial de la Hispania romana”, Studia Historica. Historia Antigua, 20, pp. 139-170.

Quilici, L. (1974): “Collatia”. En AA. vV.: Forma Italiae, I, X. Roma.

Rodríguez Aguilera, A. (2011): "Restos de muro de parcelación de época romana aparecido en PP. Escolapios”. En Orfila, M.: Florentia Iliberritana. La ciudad de Granada en época romana. Granada: UGR, pp. 164-165.

Rodríguez Aguilera, A.; García-Consuegra, J. M.; Rodríguez Aguilera, J. y Pérez Tovar, M. J. (2013-14): "La villa romana de los Mondragones (Granada). Un nuevo yacimiento arqueológico en el entorno de Iliberis", Romula, 12-13, pp. 475-501.

Román Punzón, J. M. (2004): El mundo funerario rural en la provincia de Granada durante la Antigüedad Tardía. Monumenta Regni Granatensis Historica. Granada: UGR.

Roth Congès, A. (1996): “Modalités pratiques d'implantation des cadastres romains: quelques aspects (Quintarios claudere. Perpendere. Cultellare. Varare: la construction des cadastres sur une diagonale et ses traces dans le Corpus Agrimensorum)", Mélanges de l'École Française de Rome, 108, 1, pp. 299-422.

Ruiz Montes, P.; Peinado Espinosa, M. V.; Ayerbe López, J. L.; Gómez Timón, P.; García-Consuegra Flores, J.; Morcillo Matillas, F. J.; Rodríguez Aguilera, J.; Gómez Fernández, A.; Jiménez de Cisneros, M. y López, R. (2013): "Producción cerámica en el ager Iliberritanus hacia fines de la República: el asentamiento productivo de Parque Nueva Granada”. En Bernal, D.; Juan, L. C.; Bustamante, M.; DíAz, J. J. y SÁez, A. M. (eds.): Hornos, talleres y focos de producción alfarera en Hispania. Monografías Ex Officina Hispana. Cádiz, t. I, pp. 307-316.

Ruiz Torres, S. y Padial, J. (2004): "Intervención arqueológica de urgencia en la villa romana de Híjar (Las Gabias)". En Anuario Arqueológico de Andalucía 2001. Sevilla, t. III, pp. 463-467.

Sánchez López, E.; Orfila, M. y Moreno, A. S. (2008): "Las actividades productivas de los habitantes de Florentia Iliberritana”. En Orfila, M. (ed.): Granada en época romana: Florentia Iliberritana. Granada, pp. 101-116.

SÁnchez Moreno, A. (2010): "Intervención arqueológica de urgencia en c/ Cruces y c/ La Viña, Ogíjares (Granada)". En Anuario Arqueológico de Andalucía 2005. Sevilla, pp. 1174-1183.

Serrano, E. (1976): "La cerámica romana de los hornos de Cartuja (Granada)", Cuadernos de Prehistoria Univ. de Granada, 1, pp. 215-233.

Sotomayor, M. (1966a): "Excavaciones en la huerta de la Facultad de Teología de Granada”, NAH, 8-9, pp. 193-202.

Sotomayor, M. (1966b): "Alfar romano en Granada”. En IX CAN (Valladolid, 1965), pp. 367-372.

Sotomayor, M. (1970): "Siete hornos de cerámica romana en Granada con producción de sigillata”. En XI CAN (Mérida, 1968), pp. 713-728.

Thullin, C. (1971 [1913]): Corpus Agrimensorum Romanorum. Opvscula Agrimensorvm Vetervm. Stutgardiae in Aedibus. B.C. Reubneri. Stuttgart: Teubner.

WALlACE-HADRILl, A. (1988): "The social structure of the Roman house", Papers of the British School at Rome, LVI, pp. 43-97.

Wheatley, D. W. y Gillings, M. (2000): "Vision, perception and GIs: developing enriched approaches to the study of archaeological visibility”. En Lock, G. (ed.): Beyond the Map. Archaeology and Spatial Technologies. NATO Science Series A, Life Sciences, vol. 321. Amsterdam: Ios Press, pp. 1-27. 
